\title{
Anatomy and evolution of a cyclonic mesoscale eddy observed in the northeastern Pacific tropical-subtropical transition zone
}

\author{
J. A. Kurczyn, ${ }^{1}$ E. Beier, ${ }^{2}$ M. F. Lavín, ${ }^{1}$ A. Chaigneau, ${ }^{3}$ and V. M. Godínez ${ }^{1}$ \\ Received 6 August 2013; revised 14 October 2013; accepted 14 October 2013.
}

[1] In November 2005 off Cabo Corrientes, a cyclonic eddy was sampled from (i) remotely sensed data of sea level anomaly, near-surface wind, chlorophyll- $a$ concentration and sea surface temperature and (ii) direct observations from a lowered Acoustic Doppler profiler, and a conductivity, temperature, and depth sensor. The sea level anomaly data set and an automated eddy detection method showed that this vortex formed near the Mexican coast and traveled westward/northwestward, $\sim 1000 \mathrm{~km}$ into the open ocean for $\sim 8$ months. Surface winds and currents indicated that the cyclone was generated during a coastal upwelling event that occurred simultaneously with an equatorward flow located close to the coast. During its growing phase, the eddy extended from the surface to $750 \mathrm{~m}$ depth and mixed the water column in the first $\sim 100 \mathrm{~m}$, showing an eastward shift of the eddy axis toward the sea surface of $1.5^{\circ}$ of longitude, that generated a southward meridional heat transport in the upper layers. Integrated in the vertical, this heat transport accounted for a total of $-105 \times 10^{12} \mathrm{~W}$, within the region of the eddy. The estimation of the available heat and salt anomaly contents revealed that the eddy transported relatively cold, salty, and anoxic waters associated with the Subtropical Subsurface water mass. While traveling offshore, the cyclonic eddy also exhibited relatively higher chlorophyll $a$ concentrations at the sea surface than its surroundings. Comparison of some surface properties estimated from satellite and in situ data showed that satellite data tend to underestimate its amplitude and orbital geostrophic velocity.

Citation: Kurczyn, J. A., E. Beier, M. F. Lavín, A. Chaigneau, and V. M. Godínez (2013), Anatomy and evolution of a cyclonic mesoscale eddy observed in the northeastern Pacific tropical-subtropical transition zone, J. Geophys. Res. Oceans, 118, doi:10.1002/ 2013JC009339.

\section{Introduction}

[2] Mesoscale eddy activity has been intensively studied in the northeastern tropical Pacific especially in the Gulfs of Tehuantepec and Papagayo [Stumpf and Legeckis, 1977; Clarke, 1988; McCreary et al., 1989; Barton et al., 1993, 2009; Trasviña et al., 1995; Lluch-Cota et al., 1997; Chelton et al., 2000a, 2000b; Palacios and Bograd, 2005; Zamudio et al., 2006; Trasviña and Barton, 2008; Liang et al., 2012]. In these regions, mesoscale eddies can reach large sizes and travel far into the open ocean, in comparison to eddies formed in other regions of the northeastern Pacific. However, using satellite altimetry it has also been recognized that there are other near-coastal hotspots for the

\footnotetext{
${ }^{1}$ Departamento de Oceanografía Física, CICESE, Ensenada, Baja California, Mexico.

${ }^{2}$ CICESE Unidad La Paz, La Paz, Baja California Sur, Mexico.

${ }^{3}$ Laboratoire d'Études en Géophysique et Océanographie Spatiale, IRD, CNRS, CNES, UPS, Toulouse, France.

Corresponding author: J. A. Kurczyn, Departamento de Oceanografía Física, CICESE, Carretera Ensenada-Tijuana No. 3918, Zona Playitas, Ensenada, Baja California 22860, Mexico. (alexk@cicese.edu.mx)

(C) 2013. American Geophysical Union. All Rights Reserved. 2169-9275/13/10.1002/2013JC009339
}

generation of mesoscale eddies in the northeastern Pacific [Morrow et al., 2004; Stegmann and Schwing, 2007; Henson and Thomas, 2008; Chaigneau et al., 2009; Chelton et al., 2011; Kurczyn et al., 2012]. In particular in the study area (Figure 1), Kurczyn et al. [2012] showed that eddies in Cabo Corrientes are generated near the coast, with a production of $7 \pm 3$ long-lived eddies per year (that is, eddies that lasted more than 10 weeks), with more cyclones being generated than anticyclones. From their observations of 125 long-lived eddies produced in this same region between 1992 and 2010, these authors reported that anticyclones (cyclones, respectively) can translate in average for more than $\sim 700$ (450) $\mathrm{km}$ from the coast to the open ocean.

[3] Several physical mechanisms have been shown to be involved in the generation of surface mesoscale eddies in this area, such as surface wind forcing, lateral current shear, and/or popagation of coastally trapped waves of equatorial origin [Parés-Sierra et al., 1993; Zamudio et al., 2007; Pantoja et al., 2012]. In particular, for the surface eddies in Cabo Corrientes, Kurczyn et al. [2012] showed that the maximum anticyclonic (cyclonic) eddy generation occurs in October (April) and present a strong seasonal variability (semiannual variability). Cyclonic and anticyclonic eddy productions were qualitatively associated to peaks in the 


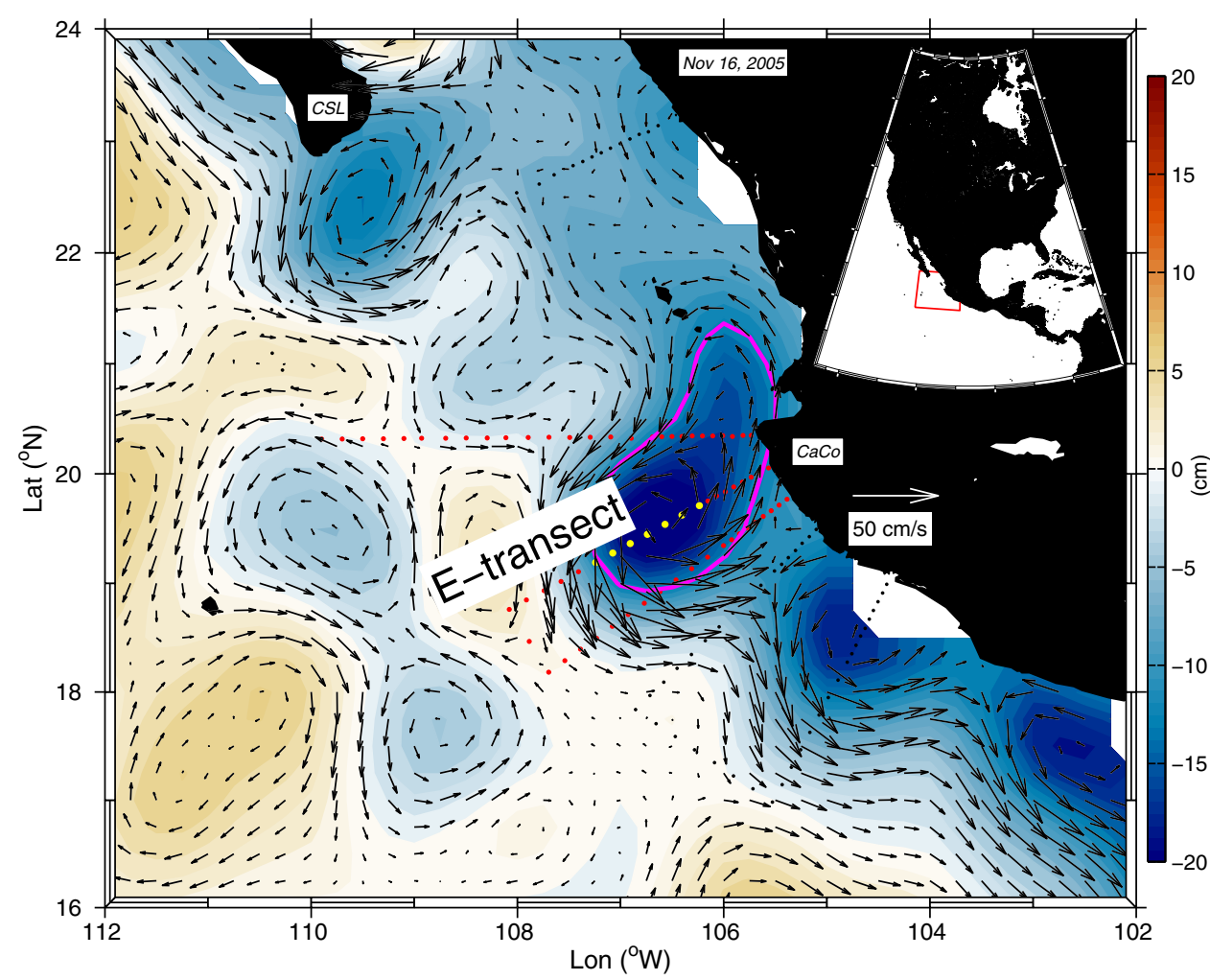

Figure 1. Sea level anomaly (SLA in cm, color shading) and associated surface geostrophic circulation observed in the Cabo Corrientes (CaCo) region for 16 November 2005. The pink contour delimits the cyclonic eddy investigated in this study as identified by the sea level anomaly-based method (see text for details). Dots show the locations of the PROCOMEX-0511 CTD/LADCP stations, where the red dots represent the transects used to reconstruct its 3-D structure, while yellow dots represents the stations located inside the eddy core. CSL stands for Cabo San Lucas.

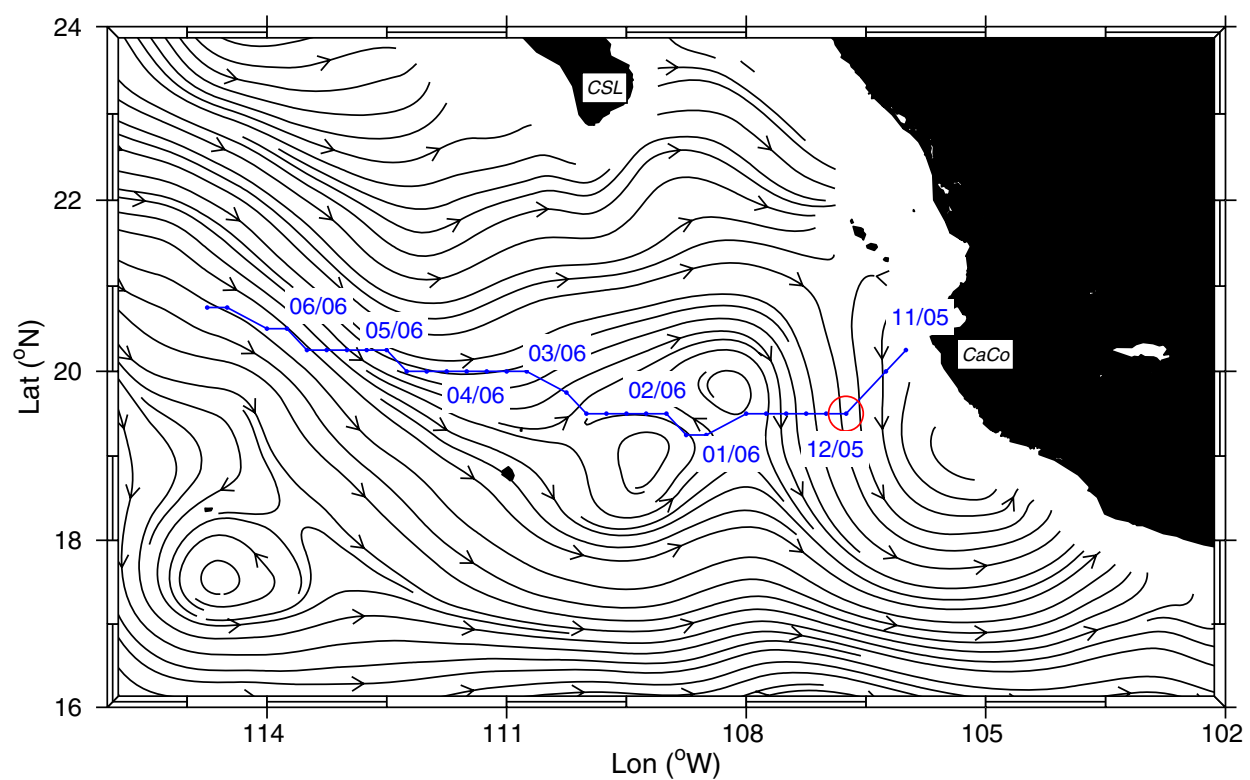

Figure 2. Trajectory followed by the CE as it traveled offshore (blue dotted line) with its corresponding dates. Beneath are the stream lines of the mean surface geostrophic flow (from November to June), referenced to the $1027 \mathrm{~kg} / \mathrm{m}^{3}$ isopycnal. The red circle corresponds to the time when the vortex was sampled by the PROCOMEX-0511 cruise. Note the eddy westward translation mainly against the current flow. 

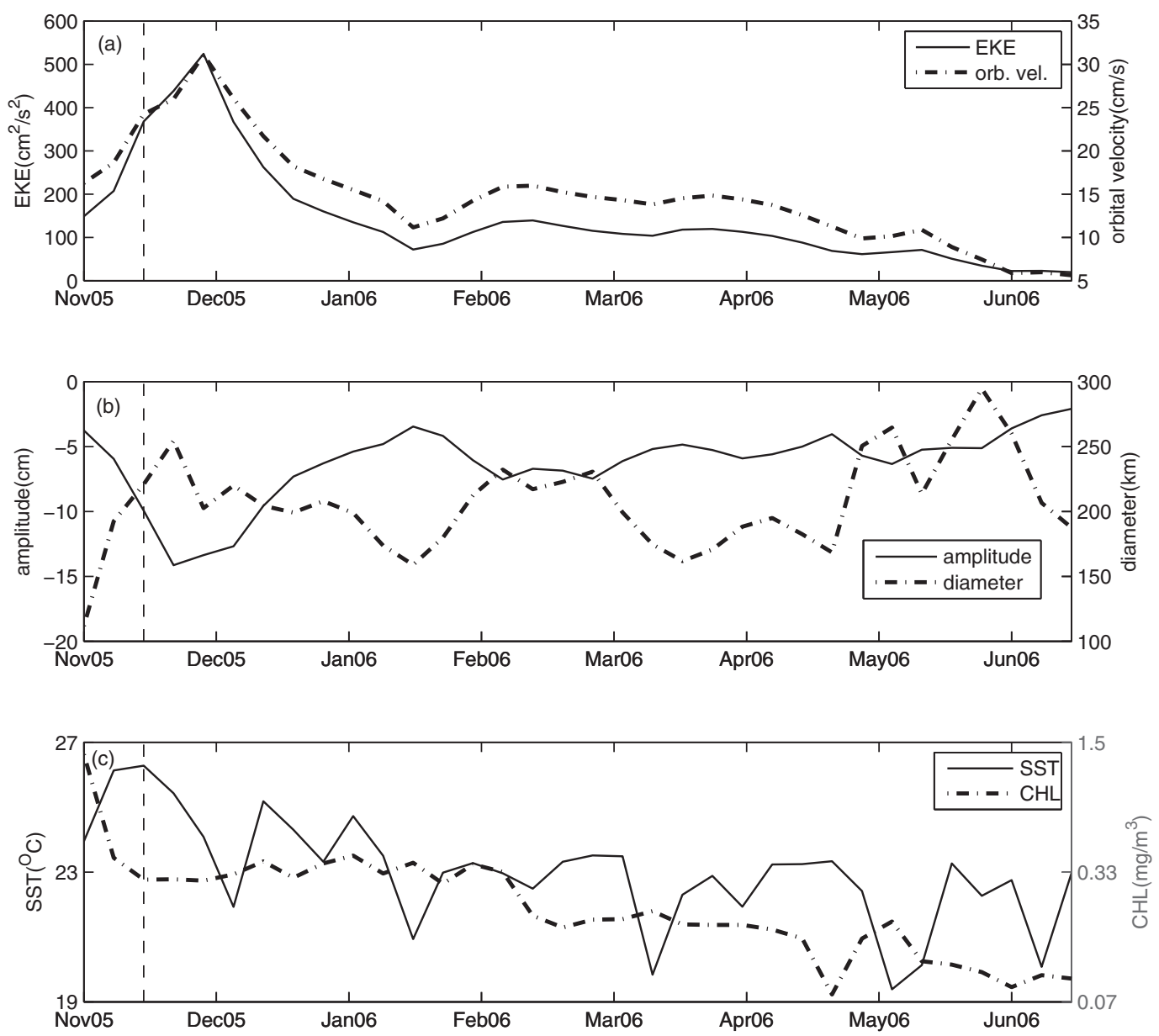

Figure 3. Time series of the CE surface properties during its life span: (a) eddy kinetic energy (EKE, left axis, in $\mathrm{cm}^{2} / \mathrm{s}^{2}$ ) and orbital velocity (right axis, $\mathrm{cm} / \mathrm{s}$ ), (b) amplitude (left axis, in $\mathrm{cm}$ ) and diameter (right axis, in $\mathrm{km}$ ), and (c) sea surface temperature (SST, left axis in ${ }^{\circ} \mathrm{C}$ ) and chlorophyll- $a$ concentration (CHL, right axis in $\mathrm{mg} / \mathrm{m}^{3}$ ). EKE, SST, and CHL were averaged within the CE. The vertical dashed line represents the date when the CE was sampled by the PROCOMEX-0511 cruise.

strength of the offshore surface currents and/or to the intensity of Coastal Upwelling. They also showed that Cabo Corrientes eddies had the highest mean values in translation speed, orbital velocity, and eddy kinetic energy (EKE), in comparison to two other northern coastal regions of eddy production (Cabo San Lucas and Punta Eugenia). However, the vertical structure of these eddies has never been shown.

[4] In the present study, the life story and properties of a cyclonic eddy (CE) formed in front of Cabo Corrientes in November 2005 (Figure 1) are investigated, from both remotely sensed data and direct observations. The kinematics and thermodynamical properties of this particular CE were investigated using lowered acoustic Doppler profiler (LADCP) and conductivity, temperature, depth (CTD) vertical profiles. From satellite Sea-Level Anomaly (SLA) maps and the use of an automated eddy detection scheme, the surface signature of this coherent structure was tracked from its place of generation near the coast to the open ocean and the evolution of its dynamical properties were described (i.e., orbital velocity, translation speed, amplitude, and diameter). Using other satellite data sets (nearsurface winds, sea-surface temperature (SST), and chloro- phyll- $a$ (CHL) concentration) the main forcings involved in its generation were explored as well as and the evolution of the SST and CHL inside the CE core as it traveled offshore. From ship-based measurements, the $\mathrm{CE}$ vertical structure was studied shortly after its generation. Its dynamics were largely in gradient flow balance and with this consideration is that the vertical profiles of its kinematical properties were derived and their surface expression compared against remote observations.

\section{Data and Methods}

\subsection{Satellite Data}

[5] The satellite altimetry data used in this study are the AVISO high resolution sea level anomalies, updated multimission gridded product, referred to as the Delay Time maps of sea level anomaly (DT-mslaupd). SLA maps are distributed at a 7 day interval on a $0.25^{\circ} \times 0.25^{\circ}$ longitude/ latitude grid. Mesoscale eddies are identified from these SLA maps using the "SLA-based" method developed by Chaigneau et al. [2009] and recently applied to study the main eddy characteristics in the study region from satellite 

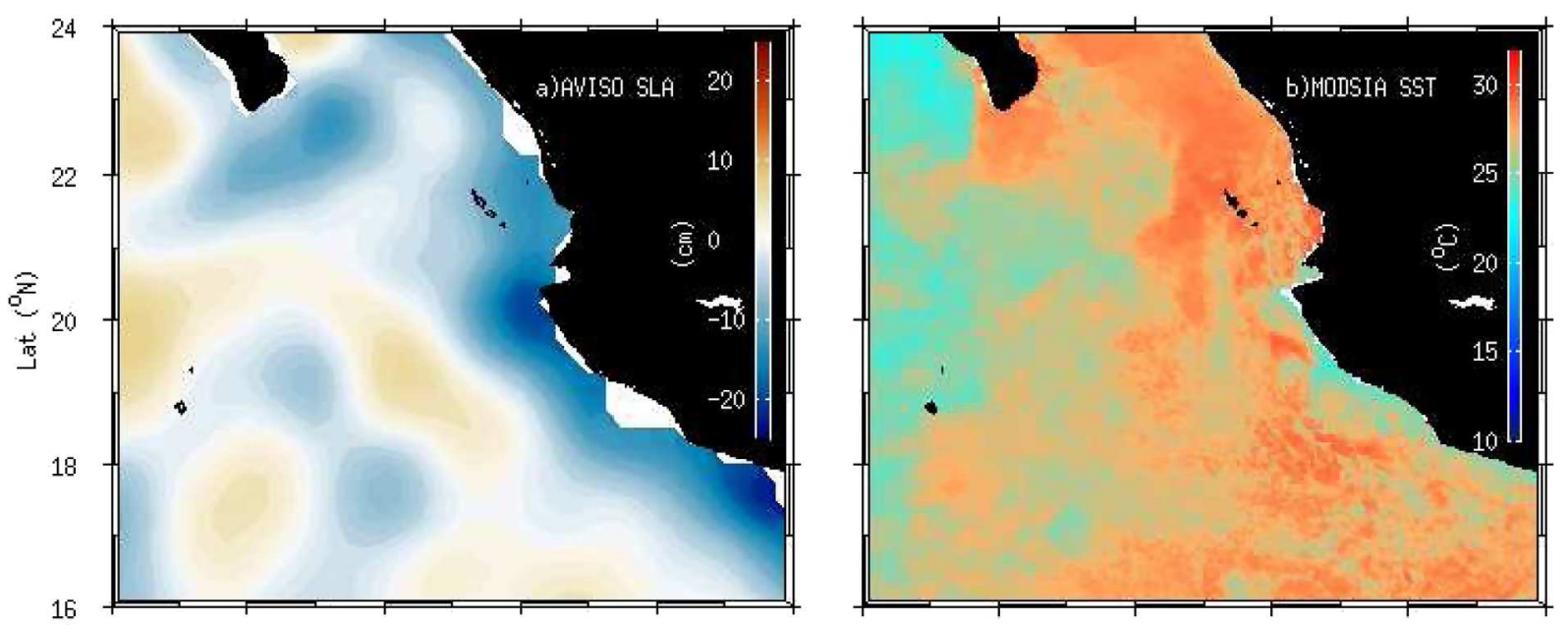

Weekly mean for 20051026
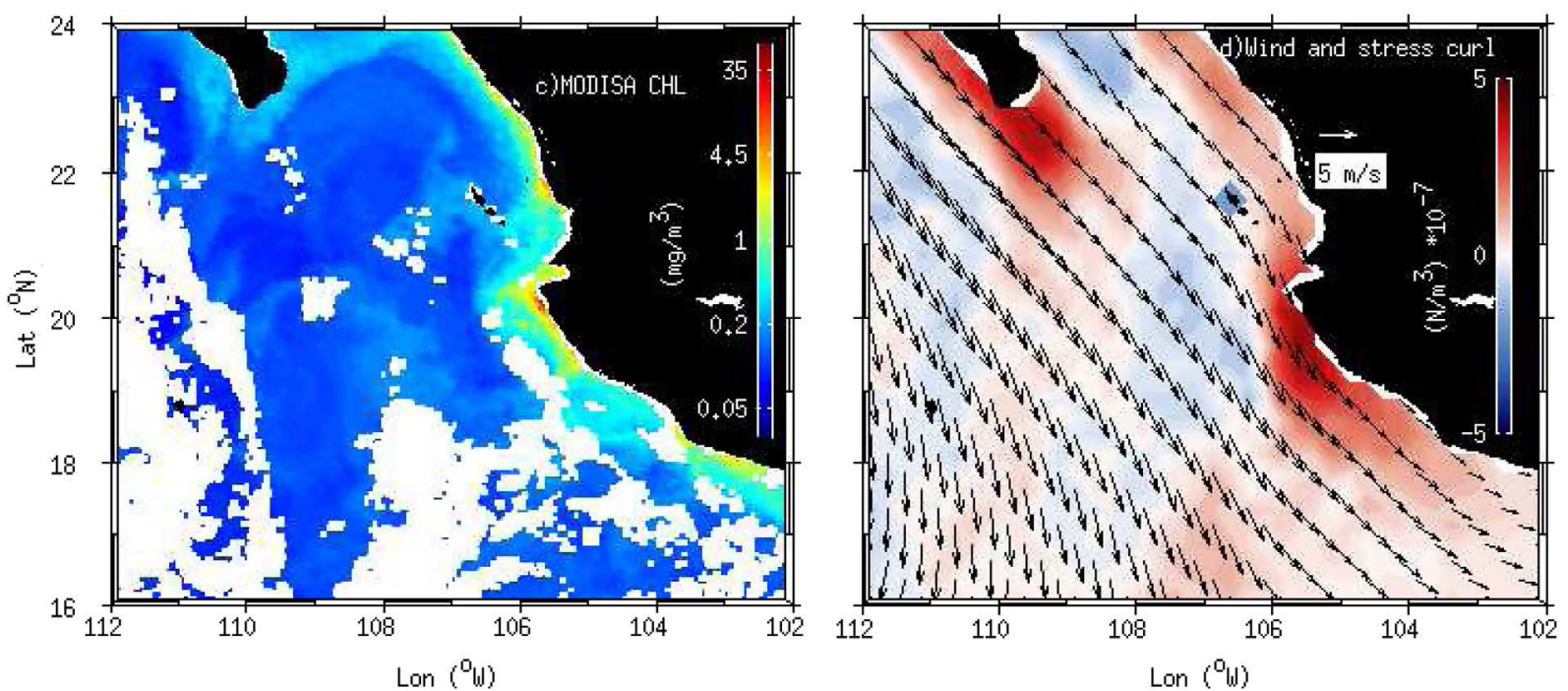

Figure 4. Surface conditions from remote sensing observations for 26 October 2005: (a) SLA (in cm), (b) SST (in ${ }^{\circ} \mathrm{C}$ ), (c) CHL (in $\mathrm{mg} / \mathrm{m}^{3}$ ), and (d) wind (in $\mathrm{m} / \mathrm{s}$ black arrows) and wind stress curl (in $10^{-7} \mathrm{~N} /$ $\mathrm{m}^{3}$, color shading).

altimetry [Kurczyn et al., 2012]. Readers interested in more detail on the SLA data set and the eddy detection scheme are referred to Kurczyn et al. [2012]. An example of SLA map and the edge detection of the particular CE investigated in this study is shown in Figure 1.

[6] Sea surface winds were analyzed to depict the atmospheric state and estimate an upwelling index at the time the eddy was generated. The wind product comes from the Cross-Calibrated Multi-Platform (CCMP) project [Atlas et al., 2011] and is distributed by the NASA JPL PO.DAAC. The L3.0 product having a $0.25^{\circ}$ spatial resolution and distributed at $6 \mathrm{~h}$ time interval were used. In order to match the dates of the AVISO data, weekly averages from the $6 \mathrm{~h}$ interval product were constructed. The surface wind stress and wind-stress curl (WSC) were computed from the wind speed and direction as in Trenberth et al. [1989].

[7] To investigate the signature of the $\mathrm{CE}$ on the surface CHL concentration and SST, the CHL and SST maps of the MODIS-Aqua mission were used; they are also distributed by the NASA JPL PO.DAAC (http://podaac.jpl.nasa.gov), at daily intervals and $4 \mathrm{~km}$ space grid. In order to match the dates of the AVISO data, weekly averages from the daily SST and CHL products were also constructed.

\subsection{In Situ Data}

[8] Since 2002, the study region is repetitively sampled by the PROCOMEX (PRograma OCeanográfico del Occidente de MÉXico) hydrographic surveys. In November 2005, the PROCOMEX-0511 oceanographic survey sampled a CE in front of Cabo Corrientes (Figure 1). Vertical potential temperature, salinity, and dissolved oxygen concentration profiles were acquired from the surface to $1500 \mathrm{~m}$ (or to $\sim 5 \mathrm{~m}$ above the bottom if shallower), using a CTD model Sea-Bird SBE-911 plus equipped with an oxygen sensor. For more information about the processing of the CTD data readers are referred to Godinez et al. [2006]. Vertical profiles of current speed and direction were acquired using an RDI $300 \mathrm{kHz}$ LADCP with $8 \mathrm{~m}$ vertical 

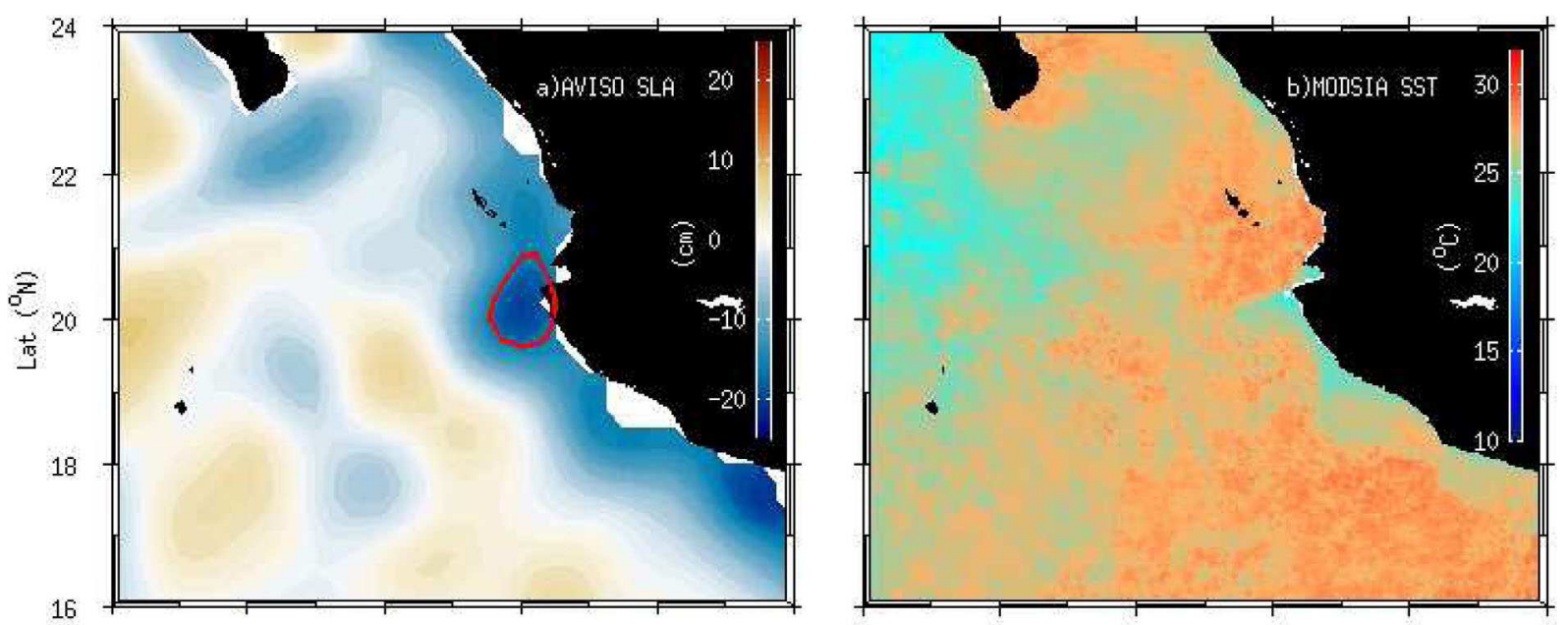

Weekly mean for 20051102
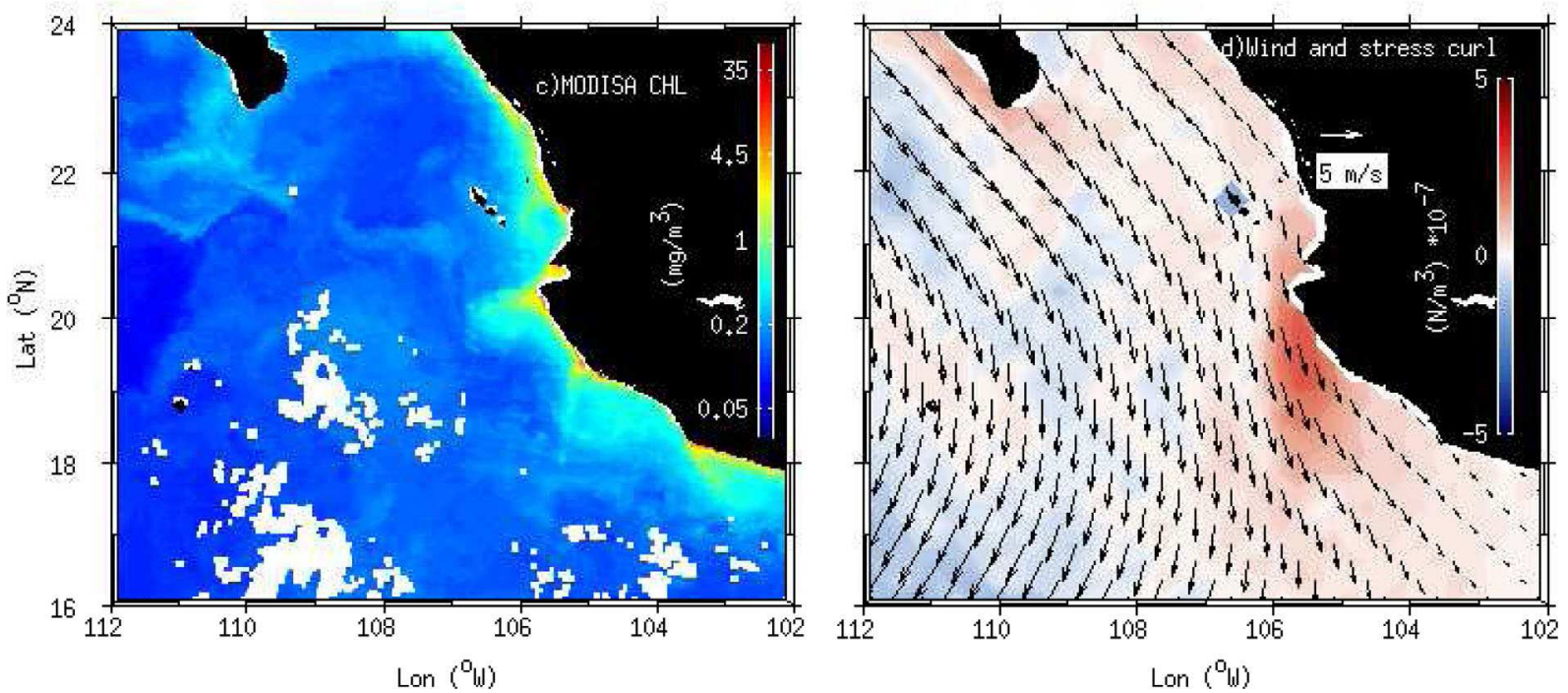

Figure 5. Same as Figure 4 but for 2 November 2005 corresponding to the time when the CE was generated. Red contour in (a) delimits the CE identified by the sea level anomaly-based method.

bins. The data were processed using LDEO IX.7 software from Colombia University [Thurnherr, 2011].

[9] The PROCOMEX-0511 cruise lasted 17 days (5-21 November 2005) and three cross-shore transects (red dots in Figure 1) sampled the CE approximately in one week (10-16 November 2005). In order to reconstruct the threedimensional structure of the CE from the surface to $1500 \mathrm{~m}$ depth, the vertical profiles acquired by the CTD and LADCP were objectively interpolated horizontally at each depth level with a decorrelation scale of $\mathrm{Lx}=100 \mathrm{~km}$ and $\mathrm{Ly}=130 \mathrm{~km}$, which in the east-west direction is about twice the size of the local internal Rossby radius of deformation $(\sim 52 \mathrm{~km})$.

\subsection{Thermodynamics}

[10] To estimate how much water could have been mixed by the cyclonic eddy, the distribution of temperature, salt, and dissolved oxygen concentration in the transect that cut the vortex close to its core was studied (E-transect, see Fig- ure 1). The anomalies of such parameters were quantified by removing climatological profiles obtained from the CSIRO Atlas of Regional Seas (CARS) [Ridgway et al., 2002].

\subsection{Dynamical Analysis}

[11] As mentioned by other authors [Olson, 1980; Takahashi et al., 2007; Sangrà et al., 2007; Rossby et al., 2011], the dynamics of mesoscale eddies cannot be totally explained by the geostrophic balance, especially near the eddy center where the Rossby number can be relatively large, and ageostrophic motions and centrifugal effects can be important [e.g., Pingree and Le Cann, 1992; van Aken, 2002; Chaigneau and Pizarro, 2005]. In this case, the gradient flow balance has to be considered since it takes into account the equilibrium between the Coriolis, pressure gradient, and inertial forces. To analyze the dynamical structure of the observed CE, the current speed measured by the LADCP was used. Assuming that eddies are axisymmetric 


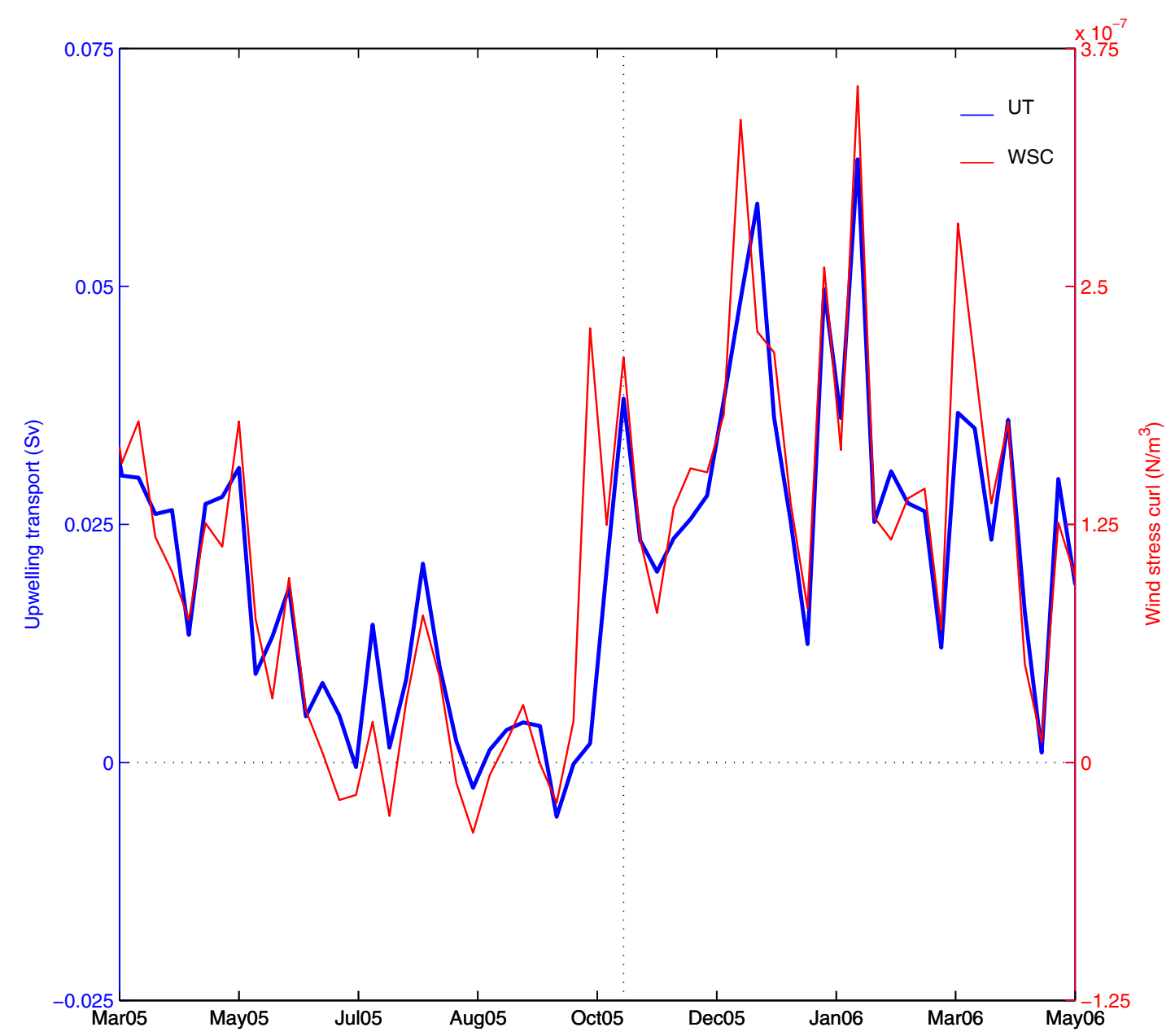

Figure 6. Time series of the upwelling transport (UT) and wind stress curl (WSC) for the dates near the upwelling event (vertical dot line, 26 October 2005). For the date of the upwelling event, the upwelling transport showed $0.045 \mathrm{~Sv}$, and the wind stress curl $2.4 \times 10^{-7} \mathrm{~N} / \mathrm{m}^{3}$.

and have a circular shape, as this is the case for a large part of the world ocean eddies [e.g., Chelton et al., 2011], the momentum equation for steady flow in cylindrical coordinates can be expressed as:

$$
\frac{v^{2}}{r}+f v=\frac{1}{\rho} \frac{\partial p}{d r}=f v_{g}
$$

where $v$ is the gradient flow orbital velocity (measured by the LADCP), $v_{g}$ is the geostrophic orbital velocity, $f$ is the Coriolis parameter, $\rho$ is the water density, $p$ is the pressure, and $r$ is the radial distance from the eddy center. In a CE, the pressure gradient balances the Coriolis force and the centrifugal force, making the gradient flow balance to be subgeostrophic.

\section{Results}

\subsection{Satellite Observations}

[12] The observed CE (Figure 1) was sampled by the PROCOMEX-0511 cruise 3 weeks after it was generated near the coast, giving the opportunity to compare the or- bital velocity, $U$, eddy kinetic energy (EKE), diameter and amplitude observed from satellite altimetry and in situ data.

[13] Figure 2 shows the path followed by this CE from the coast to the open ocean; it was generated on 2 November 2005 and lasted 238 days ( $\sim 8$ months) before dissipating on 21 June 2006. It drifted westward-northwestward with a mean speed of $\sim 5 \mathrm{~cm} / \mathrm{s}$ traveling more than $\sim 1000$ $\mathrm{km}$, in agreement with the mean eddy properties observed by Kurczyn et al. [2012] off Cabo Corrientes. During its life time, the CE traveled through different oceanic conditions and climatic seasons; it was generated in mid-autumn near the coast where tropical currents are commonly observed (in particular the Mexican Coastal Current, see Kurczyn et al. [2012]), and traveled to the tropicalsubtropical transition zone during winter (where the tropical branch of the equatorward California Current is located) before it ended in late-spring inside this area.

[14] The time series of the CE surface properties (Figures $3 \mathrm{a}$ and $3 \mathrm{~b}$ ) show that when this eddy was sampled by the PROCOMEX-0511 cruise (dashed vertical line in Figure 3 ) it was in a growing phase associated with an increase of its size, amplitude, and mean EKE. One month later (December 2005), the CE reached a mature state, characterized 


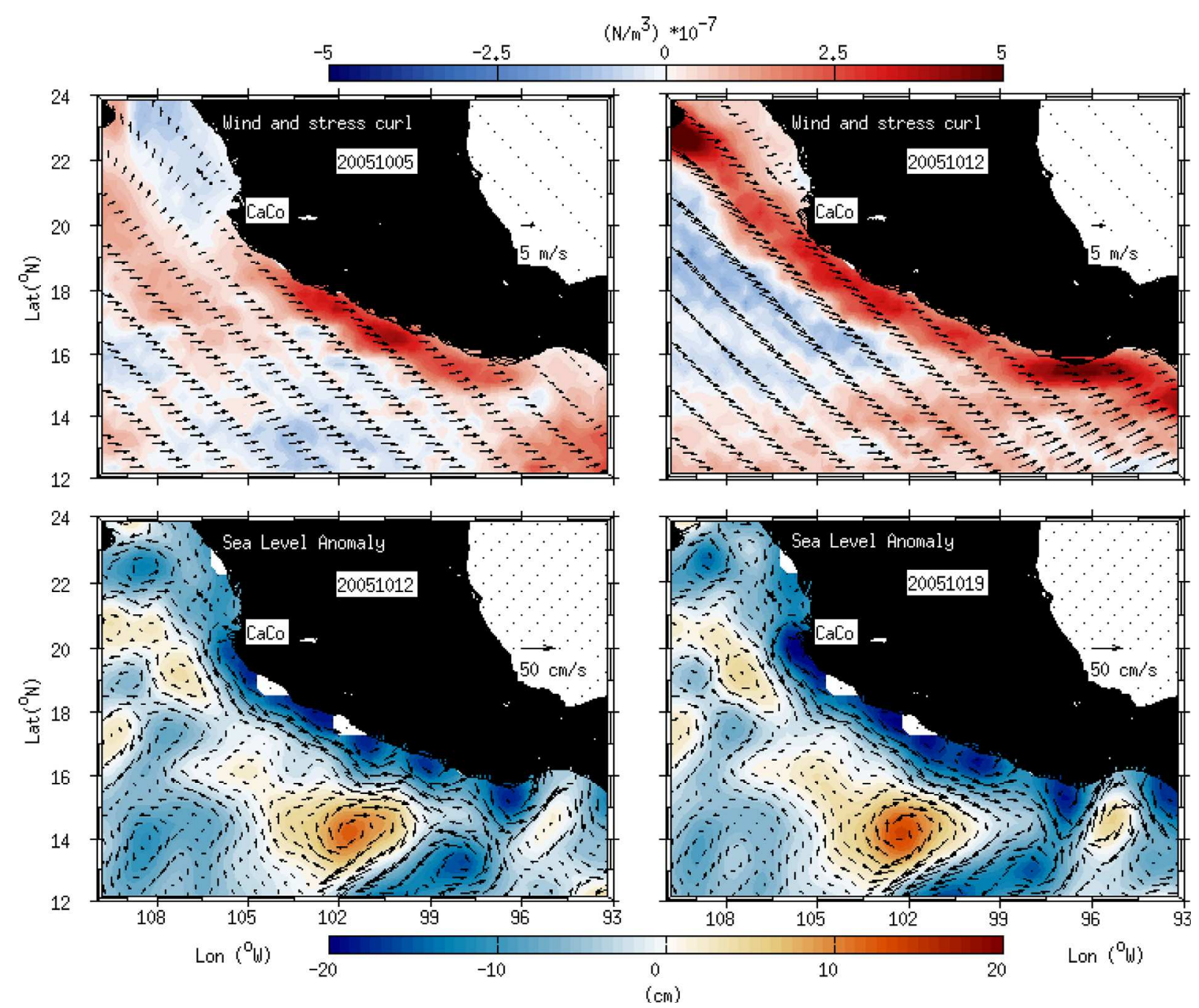

Figure 7. Sequence of two weeks showing the response of the ocean surface to wind forcing, with a one week lag between them. (top) Vectors of CCMP surface winds (in $\mathrm{m} / \mathrm{s}$ ) with its corresponding wind stress curl (color shading, in $10^{-7} \mathrm{~N} / \mathrm{m}^{3}$ ). (bottom) AVISO SLA (color shading, in $\mathrm{cm}$ ) and their associated vectors of surface geostrophic flow (in $\mathrm{cm} / \mathrm{s}$ ). This phenomenon persisted for 1 month before the CE was generated.

by a maximum EKE, amplitude, and diameter. Then, these variables tend to decrease with time, illustrating the decay of the eddy as it traveled offshore (in the case of the diameter this was not so evident). From the remote observations of CHL and SST inside the CE core, time series of these two surface variables were constructed along the eddy path (Figure 3c). Near the coast at the beginning of these series, it shows high CHL and relatively low SST, which is due to the upwelling event that occurred before the eddy was generated (see below).

[15] On the other hand, while the eddy was traveling offshore both CHL and SST fields tended to decrease with time. In the case of the CHL, its distribution shows a typical behavior, diminishing from a maximum near the coast to a minimum in the open ocean. In the case of the SST, the time series shows a more dynamic evolution since it can be affected by different factors besides the eddy (like seasonal heating or cooling), with relatively cold temperatures $\left(\sim 24^{\circ} \mathrm{C}\right)$ due to the upwelling near the coast, and then a slight warming $\left(\sim 26^{\circ} \mathrm{C}\right)$ as it entered the tropical current area during the time of sampling. From mid-November 2005, the temperature inside the eddy core shows a general decrease due to the fact that it left the warm waters of the tropical system and entered the cold waters of the transition zone. The anomalies of the CHL and SST within the eddy were estimated from the monthly climatology of these variables. The CHL anomaly for each different core position (not shown), shows a greater chlorophyll concentration inside the eddy core for most of the time while traveling offshore, especially near the coast where it was affected by the upwelling event; in general this anomaly also shows how the eddy matured after being sampled and started to decay with time. In the case of the SST anomaly (not shown), it showed colder values inside the eddy core for most of its life time, although the eddy evolution is not evident, since this variable is being affected by factors outside the eddy, as mentioned before. 


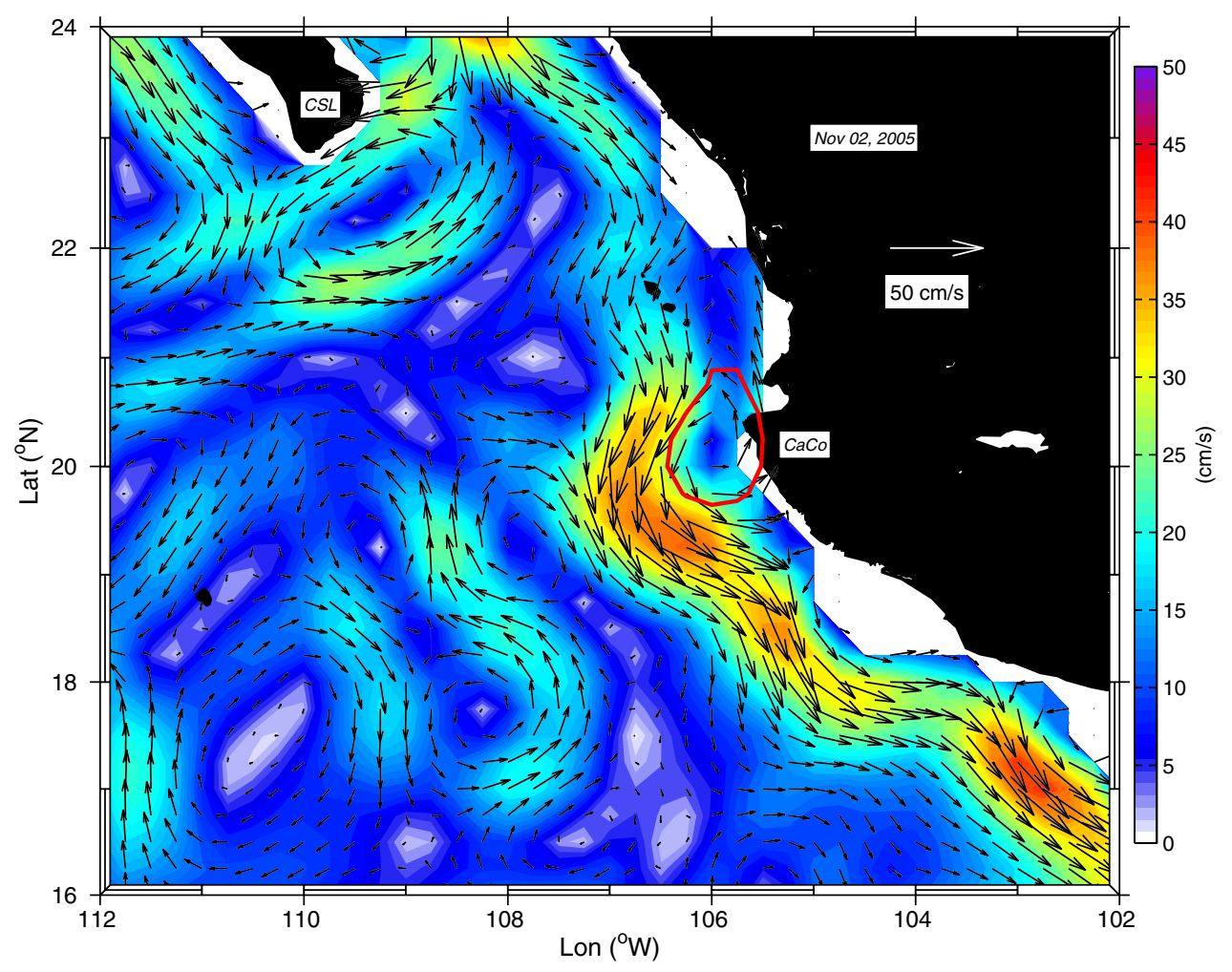

Figure 8. Surface geostrophic circulation (in $\mathrm{cm} / \mathrm{s}$ ) derived from the SLA gradients for 2 November 2005, corresponding to the time when the CE was generated. The background color is the magnitude of the flow, while the pink contour delimits the CE identified by the SLA-B method.

\subsection{Forcing Involved in the Generation of the Cyclone}

[16] Figures 4 and 5 show different satellite-sensed parameters (SLA, SST, CHL, WSC), for two consecutive weeks at the end of October and beginning of November 2005. During this period, an upwelling event occurred in front of Cabo Corrientes associated with large-scale winds blowing southeastward parallel to the coast (Figures $4 \mathrm{~d}$ and $5 \mathrm{~d})$, that influenced the generation of the CE clearly seen in SLA maps (Figures $4 \mathrm{a}$ and $5 \mathrm{a}$ ). The signature of this upwelling event is also observed in both the SST (Figures $4 \mathrm{~b}$ and $5 b$ ) and CHL (Figures $4 c$ and 5c) maps. In order to analyze

Table 1. Properties of the Cyclone

\begin{tabular}{lcc}
\hline Thermodynamical properties integrated in the vertical & \\
& $(0-750 \mathrm{~m})$ & $(0-172 \mathrm{~m})$ \\
Mean annual flux $(\mathrm{Sv})$ & 0.32 & 0.072 \\
$\mathrm{AHA}\left(\times 10^{20} \mathrm{~J}\right)$ & -38 & -25 \\
$\mathrm{ASA}\left(\times 10^{12} \mathrm{~kg}\right)$ & 20 & 37 \\
$v^{\prime} T\left(\times 10^{12} \mathrm{~W}\right)$ & -105 & -99 \\
$v_{g} T_{C A R S}\left(\times 10^{12} \mathrm{~W}\right)$ & 12 & 6.5 \\
Mean dynamical properties & & \\
Diameter & 130 & 130 \\
Orbital velocity $(v$ in $\mathrm{m} / \mathrm{s})$ & 9.5 & 14.5 \\
Geostrophic velocity $\left(v_{g}\right.$ in $\left.\mathrm{m} / \mathrm{s}\right)$ & 9.7 & 21.0 \\
EKE $\left(\mathrm{cm}^{2} / \mathrm{s}^{2}\right)$ & 61 & 132 \\
$T($ days $)$ & 44 & 26 \\
Ageostrophy & 1.0 & 1.5 \\
$\zeta / f$ & 0.5 & 0.7 \\
$U / c$ & 1.1 & 1.6 \\
$R_{o}$ & 0.3 & 0.4 \\
\hline
\end{tabular}

this upwelling event at the generation site of the $\mathrm{CE}$ $\left(\sim 20^{\circ} \mathrm{N}, 106^{\circ} \mathrm{W}\right)$, the Ekman mass transport $\left(\vec{M}_{E}\right)$ was computed from the surface wind stress $\left(M_{E_{x}}=\frac{\tau_{y}}{f} ; M_{E_{y}} \frac{\tau_{x}}{f}\right)$ as well as the volume transport perpendicular to the coast $\left(Q_{x}=\frac{\Delta Y}{\rho} M_{E_{x}}\right)$; where $\Delta Y$ represents an along shore distance and $\rho=1024 \mathrm{~kg} / \mathrm{m}^{3}$ is the mean density of seawater. Considering $\Delta Y \sim 50 \mathrm{~km}$ as the along shore distance where the upwelling event occurred within the eddy contour (red circle in Figure 5a), $Q_{x}$ can be expressed now in Sverdrup units (where $1 \mathrm{~Sv}$ equals $1 \times 10^{6} \mathrm{~m}^{3} / \mathrm{s}$ ). Figure 6 shows the time series of $Q_{x}$ (blue line) and the WSC (red line) at the CE generation site; positive values of $Q_{x}$ represent offshore water flux. These results confirm that an upwellingfavorable wind event took place in November 2005 associated with both an offshore Ekman transport $\left(Q_{x}>0\right)$ and positive Ekman pumping (WSC $>0$ ). This event was followed by the generation of the studied CE (Figures 4 and 5).

[17] On the other hand, remote observations of the surface wind field show how the ocean surface along the southwestern coast of Mexico was being forced by a strong positive wind stress curl (WSC) that generated a depression in the ocean surface of the size of the wind phenomenon. This forcing persisted for a month before the appearance of the cyclone. Figure 7 shows the sequence of two of these weeks when this phenomenon occurred; the top plots depict the wind field and its wind stress curl, and the bottom plots show the response of the ocean surface to this forcing, with a 1 week lag between the wind forcing and the ocean surface response. This forcing produced an intensified equatorward flow near the coast. Figure 8 shows the surface geostrophic circulation for the time the eddy was 


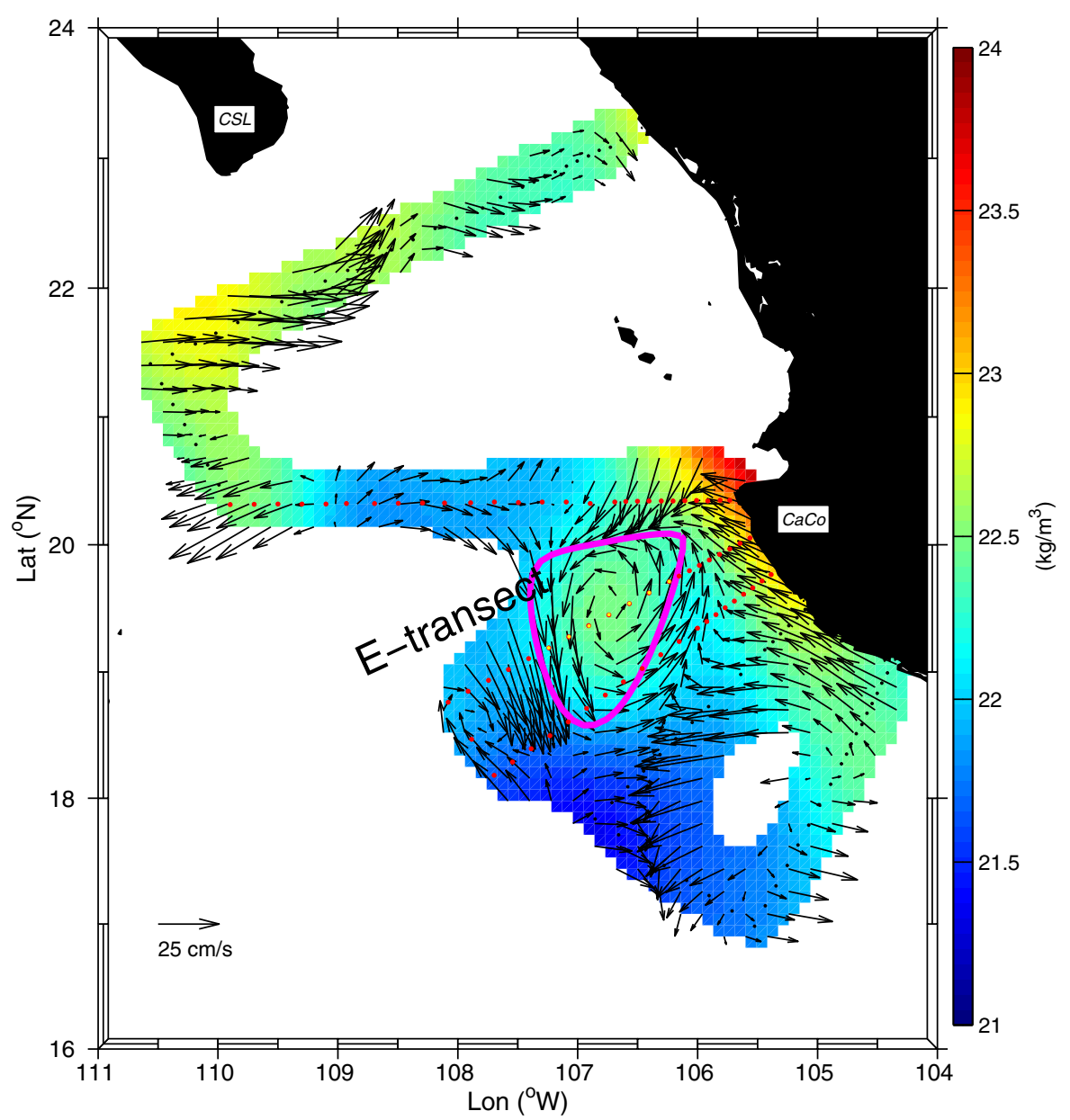

Figure 9. Surface distribution of potential density $\left(\sigma_{\theta}\right)$ with vectors of the gradient flow measured by the LADCP $(\vec{v})$, both objectively interpolated. The pink contour shows the cyclone's core surface delimiting contour, as identified by the $\zeta_{c}$ critical value. Dots show Procomex-0511 sampling stations, where the red dots represent the transects used to reconstruct its 3-D structure, and the yellow dots represent the stations located inside the eddy core. E-transect was chosen to depict the vertical distribution of some properties of this vortex (Figures 10-13).

generated. There was an intensified near-coastal equatorward flow ( $\sim 40 \mathrm{~cm} / \mathrm{s})$, whose meandering could have also been involved in the generation of the $\mathrm{CE}$.

\subsection{Eddy Thermodynamics Analyzed From the Hydrographic Observations}

[18] In this section, the impact that this eddy could have caused inside the water column is analyzed from the CTD observations. The region where this $\mathrm{CE}$ was located was objectively defined from the direct velocity observations $(\vec{v})$. The edge of the eddy core at each horizontal surface was estimated by selecting the outermost closed contour of relative vorticity $\left(\zeta=\frac{\partial v}{\partial x}-\frac{\partial u}{d y}\right)$ that intersected with the region of maximum orbital velocity, which will be defined as the critical contour $\left(\zeta_{c}\right.$, pink line in Figure 9). Figure 1 shows that the survey sampled the most dynamical part of this eddy (the eddy core), showing a region with a typical cyclonic circulation and denser water $\left(\sim 22.5 \mathrm{~kg} / \mathrm{m}^{3}\right)$ compared to the offshore ocean. Figure 9 depicts a strong poleward current close to the coast, which was not observed in geostrophic velocities derived from SLA maps (e.g., Figure 1) due to the poor resolution of the AVISO product in the near-coastal regions. This coastal poleward current represent the eastern edge of the cyclonic eddy studied here.

[19] The vertical distribution of some properties of this CE (Figures 10-13) were selected for the transect that crossed this structure close to its core (E-transect, see Figure 9). Along this transect, the isopycnal surfaces in the CE core are deformed toward the surface (Figure 10a) and flattens at $27.2 \mathrm{~kg} / \mathrm{m}^{3}(\sim 720 \mathrm{~m})$. To analyze in more detail the region where this deformation occurred, the vertical anomalies of potential temperature, salinity, and dissolved oxygen were estimated compared to CARS climatology (Figures 10b-10d, left plots, respectively). The potential temperature and salinity anomalies were used to estimate the profiles of available heat content anomaly (AHA, in $\mathrm{J} / \mathrm{m}$ ) and available salt content anomaly (ASA, in $\mathrm{kg} / \mathrm{m}$ ) per meter on the vertical, integrated over the eddy area, delimited by the $\zeta_{c}$ contour:

$$
\begin{gathered}
A H A=\int \sigma_{\theta} C_{p} \theta_{t}^{\prime} d A \\
A S A=0.001 \int \sigma_{\theta} C_{p} S^{\prime} d A
\end{gathered}
$$




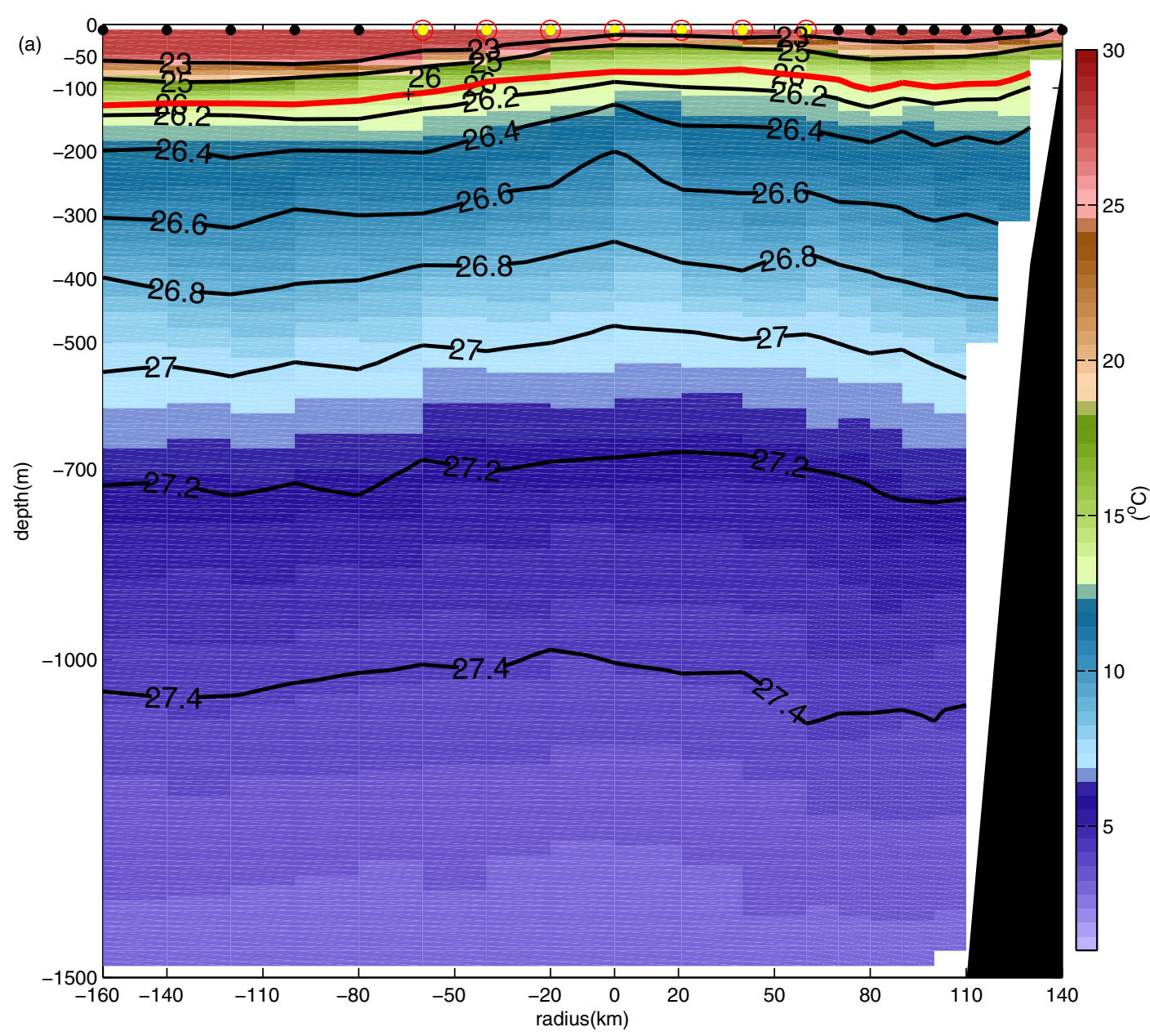

Figure 10. (a) Vertical distribution of temperature (color shading, in $\left.{ }^{\circ} \mathrm{C}\right)$ and potential density anomaly $\left(\sigma_{\theta}\right.$, black contours in $\mathrm{kg} / \mathrm{m}^{3}$ ), along the E-transect of the PROCOMEX-0511 cruise. In the region where the cyclone was located, the $\sigma_{\theta}$ contours show a convex deformation, typical of cyclonic vortex. The red contour shows the $26.0 \mathrm{~kg} / \mathrm{m}^{3}$ isopycnal. Dots at the top of the figure indicate the location of the sampling stations, whereas red and yellow dots correspond to the stations located within the CE core. (b, left plot) Potential temperature anomaly $\left(\theta_{t}^{\prime}\right)$ and (right plot) the available heat content anomaly (AHA, blue line) per vertical meter. (c, left plot) Salt anomaly $\left(S^{\prime}\right)$ and (right plot) the available salt content anomaly (AHA) per vertical meter, integrated within the eddy area (defined by the $\zeta_{c}$ contour). (d, left plot) Dissolved oxygen anomaly and (right plot) the mean dissolved oxygen anomaly concentration within the eddy area, per vertical meter (pink line).

where $\sigma_{\theta}$ is the in situ potential density $\left(\right.$ in $\left.\mathrm{kg} / \mathrm{m}^{3}\right) ; C_{p}$ is the specific heat capacity (in $\mathrm{J} / \mathrm{kg} /{ }^{\circ} \mathrm{C}$ ); the potential temperature $\left(\theta_{t}^{\prime}\right.$, in $\left.{ }^{\circ} C\right)$ and salt anomaly $\left(S^{\prime}\right.$, in psu); the factor 0.001 converts salinity to the mass of salt per unit mass of seawater; and $d A$ is the area of the eddy (in $\mathrm{m}^{2}$ ). The dissolved oxygen anomaly concentration profile represents the mean dissolved oxygen anomaly within the eddy area, per meter on the vertical (Figure 10d).

[20] Figures $11 \mathrm{~b}$ and $11 \mathrm{c}$ (right plots) show that the $\mathrm{CE}$ was associated with relatively strong negative (positive) anomalies of heat (salt) content, respectively, located between 0 and $100 \mathrm{~m}$ depth. On the other hand, the T/S diagram (not shown) showed that the mean temperature and salinity values found within the eddy corresponded to the Subtropical Subsurface water mass signature. The dissolved oxygen anomaly distribution (Figure 10d) shows that the eddy brought anoxic waters to the upper layers $(0-80 \mathrm{~m})$ typical of deeper layers in this area, although it did not seem to have affected the oxygen distributions deeper than $80 \mathrm{~m}$. Summarizing, the presence of this CE in the $\sigma_{\theta}$ distribution was detectable down to $\sim 700 \mathrm{~m}$ depth, although its major contributions in the heat, salt, and dissolved oxygen concentration were more evident from the surface to $\sim 100 \mathrm{~m}$ depth.

\subsection{Eddy Dynamics Analyzed From Hydrographic Observations}

[21] In this section, the kinematics of the CE were analyzed from the LADCP observations. The vertical distribution of geostrophic velocity $\left(v_{g}\right)$ and LADCP velocity $(v)$ along $\mathrm{E}$ transect are shown in Figure 11; in general the LADCP velocity error estimate was $12 \%$. Both fields show the cyclonic circulation of the CE qualitatively similar, however, the geostrophic magnitudes were higher (in particular between 0 and $200 \mathrm{~m}$ ), suggesting the influence of the centrifugal force in the upper layers. From this figure, it 


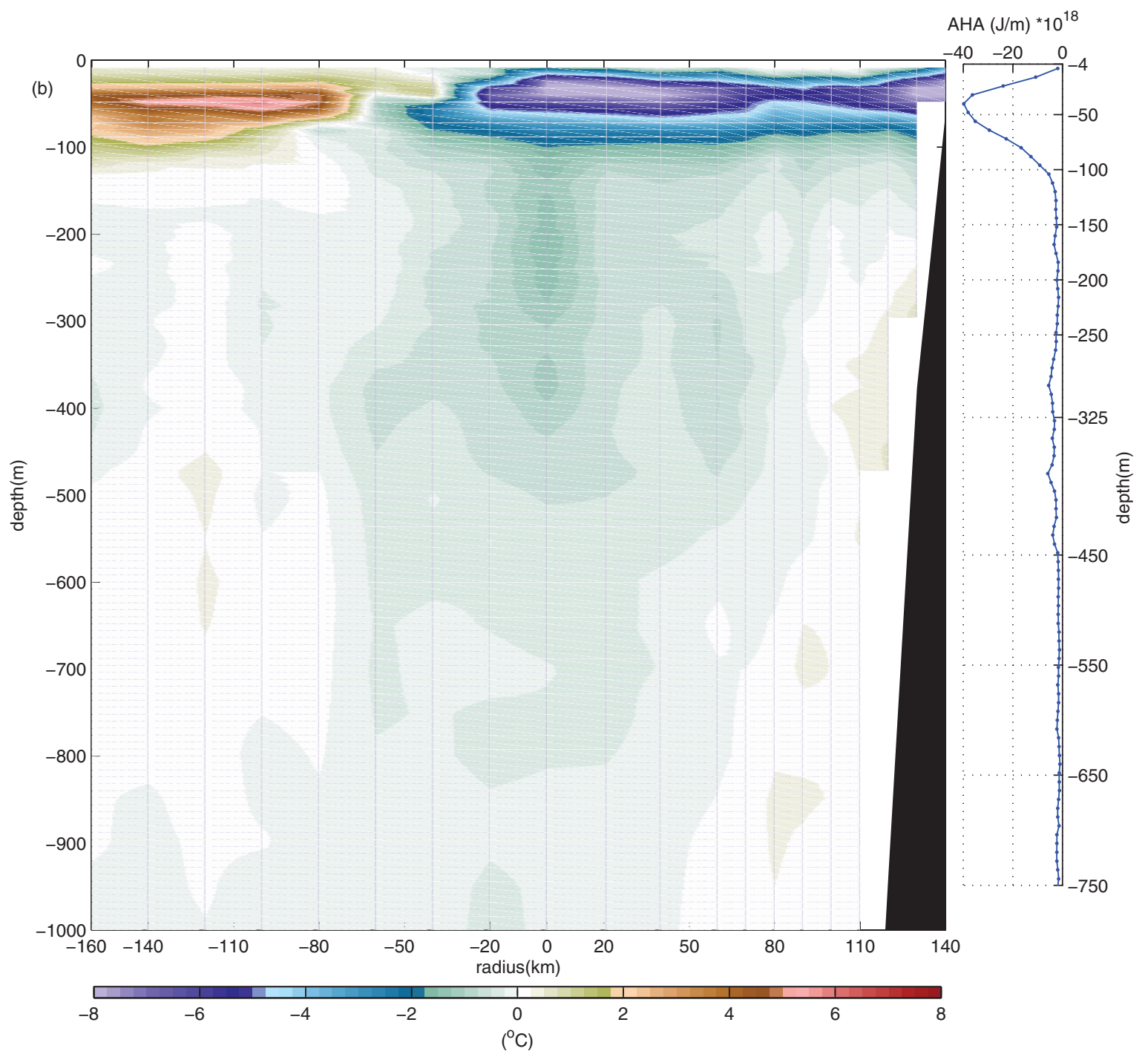

Figure 10. (continued)

is clear that the eddy extended at least to 500-700 m depth, as shown in the $\sigma_{\theta}$ vertical distribution (Figure 10a).

[22] The vertical distribution of the normalized relative vorticity $(\zeta / f)$ within the CE core was estimated from the objectively interpolated LADCP data (Figure 12, left plot). Since the vorticity field is derived from the spatial derivatives of the velocity field, this amplifies the uncertainty in the $\zeta$ estimates, and the error now is considered about twice $(24 \%)$ that of the LADCP measurements. It shows a positive vorticity of the order of 1 between 0 and $100 \mathrm{~m}$, that is, the magnitude of the vorticity of the eddy core was of the order of the planetary vorticity (where the anoxic water was) and it loses strength as it extends deeper into the water column, where the edge of the eddy core seems to be marked by the 0.45 contour. A feature of this figure and of Figure 11 is an eastward shift of eddy axis toward the sea surface (of about $1.5^{\circ}$ of longitude), which was not evident in the thermodynamic fields. In order for mesoscale eddies to produce a net transport of heat and salt, this tilt of the eddy center is crucial [e.g., Bennett and White, 1986]. As demonstrated by Roemmich and Gilson [2001], a CE axis with an eastward tilt leads to a correlation between the layer thickness and the velocity field that results in a southward transport of properties for the layers in contact with the surface, and a northward transport for the layers below.

[23] The meridional heat transport $\left(v^{\prime} T\right.$, in $\left.\mathrm{W} / \mathrm{m}\right)$ due to the eastward tilt of the $\mathrm{CE}$ axis was approximated by multiplying the in situ potential density $\left(\sigma_{\theta}\right.$, in $\left.\mathrm{kg} / \mathrm{m}^{3}\right)$ and the specific heat capacity $\left(C_{p}\right.$, in $\left.\mathrm{J} / \mathrm{kg} /{ }^{\circ} \mathrm{C}\right)$ against the correlation between the meridional component of the LADCP velocity anomaly $\left(v^{\prime}\right.$, in $\left.\mathrm{m} / \mathrm{s}\right)$ and the in situ potential temperature $\left(\theta_{t}\right.$, in $\left.{ }^{\circ} \mathrm{C}\right)$, where the LADCP velocity anomaly $\left(v^{\prime}\right.$, in $\left.\mathrm{m} / \mathrm{s}\right)$ is the difference between the velocity field and its spatial mean along E-transect $\left(v^{\prime}=v-\bar{v}\right)$. This result is presented as a profile of the meridional heat transport per vertical meter, by integrating in the radial direction $v^{\prime} T$ within the region of the eddy:

$$
v^{\prime} T=\int \sigma_{\theta} C_{p} v^{\prime} \theta_{t} d r
$$




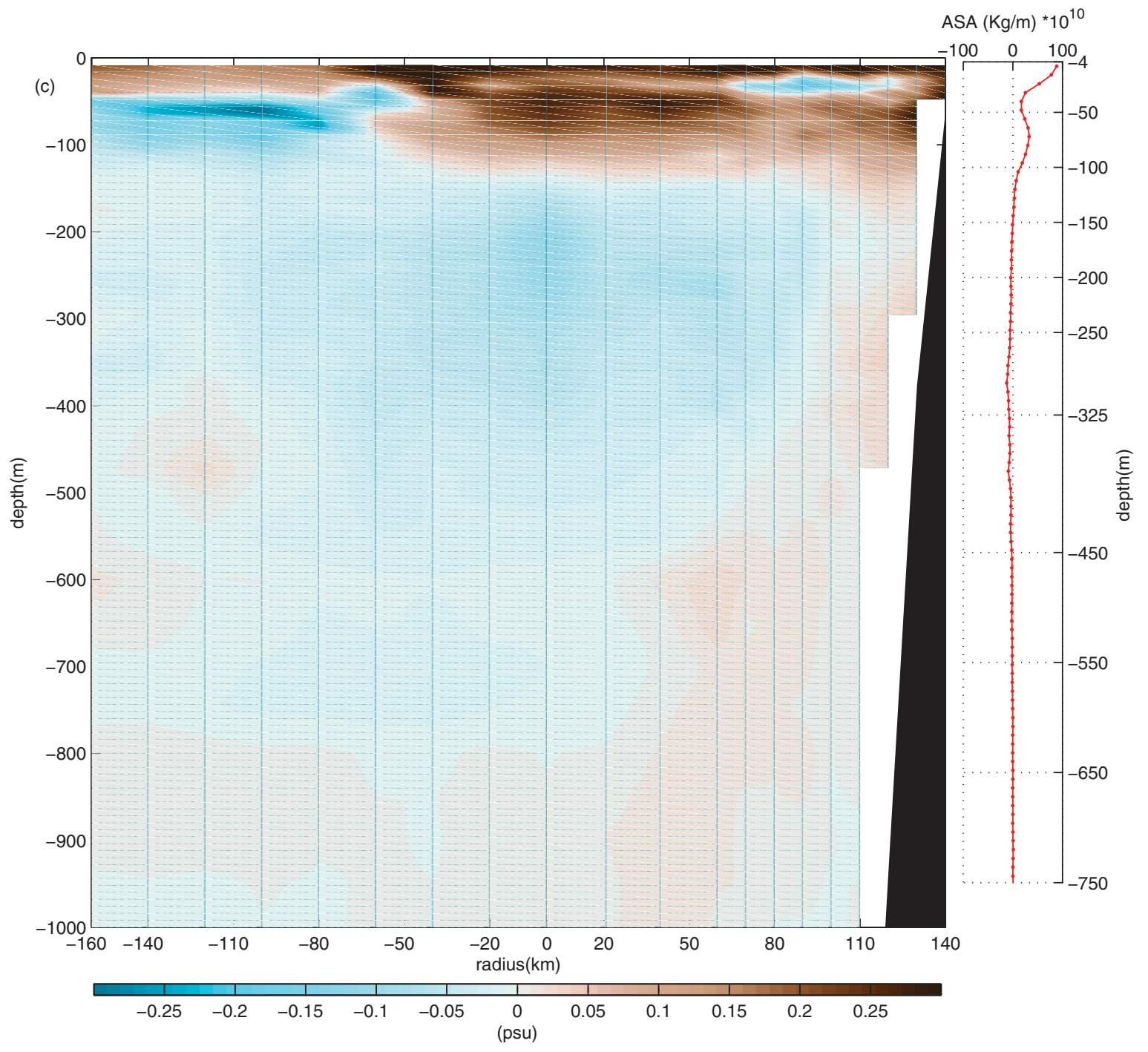

Figure 10. (continued)

where $d r$ (in $\mathrm{m}$ ) is the distance interval along the radial direction.

[24] To appreciate how much heat was being transported by the $\mathrm{CE}$, the climatological heat transport for November, along E-transect, was derived from CARS climatology and compared against the heat transported by the CE. To construct this climatological heat transport $\left(v_{g}^{\prime} T_{C A R S}\right.$, in W/m) across E-transect, a similar methodology was followed but instead it was used CARS temperature and the meridional component of CARS geostrophic velocity anomaly.

[25] Figure 12 (blue line in right plot) shows an eddy heat transport to the south in the upper $\sim 300 \mathrm{~m}$ (as explained by Roemmich and Gilson [2001]), with the maximum transport occurring between 0 and $100 \mathrm{~m}$ depth $\left(\sim-100 \times 10^{10} \mathrm{~W} / \mathrm{m}\right.$, Table 1$)$, below these layers the eddy heat transport is negligible (i.e., there is no northward transport). Figure 12 (red line in right plot) shows that geostrophic currents in November have a climatological heat transport to the north in the upper layers, contrary to what the eddy exhibited, and of one order of magnitude smaller $\left(\sim 10 \times 10^{10} \mathrm{~W} / \mathrm{m}\right)$ than the heat transport due to the CE. These results demonstrate the impact that the eddy had in the upper layers, and its importance in mixing and redistributing properties in the water column.

[26] To determine additional characteristics of this CE from the LACDP and CTD data the profiles of different parameters were estimated within the limits of the eddy core $\left(\zeta_{c}\right)$. These were: (1) amplitude (in $\mathrm{cm}$ ), defined as the absolute value of the difference between maximum and minimum geopotential anomaly; (2) diameter (in $\mathrm{km}$ ), defined as the diameter of an equivalent circular vortex having the same area as the area defined by the $\zeta_{c}$ contour; (3) normalized relative vorticity, defined as the mean relative vorticity $(\bar{\zeta})$ divided by the planetary vorticity $(f)$. Under gradient flow balance, this last parameter corresponds to twice the Rossby number $\left(R_{o}=\left|\frac{v}{f r}\right|\right)$. Assuming that the eddy was in solid body rotation, the orbital velocity of the eddy is $v=\omega r$, where $\zeta \cong 2 \omega$ and $\omega$ is the angular velocity; therefore, $R_{o}$ can then be written as $R_{o}=\left|\frac{\omega}{f}\right|=\left|\frac{\zeta}{2 f}\right|$ [Kundu and Cohen, 2002; Takahashi et al., 2007]; (4) Rotational period (in days) $T=\frac{2 \pi}{\omega}=\frac{4 \pi}{\zeta}$. (5) Eddy kinetic energy (EKE, in $\mathrm{cm}^{2} / \mathrm{s}^{2}$ ), defined as the mean value of the kinetic energy within the CE. (6) Ageostrophic contribution (in $\mathrm{cm} / \mathrm{s}$ ), defined as the difference between the mean 


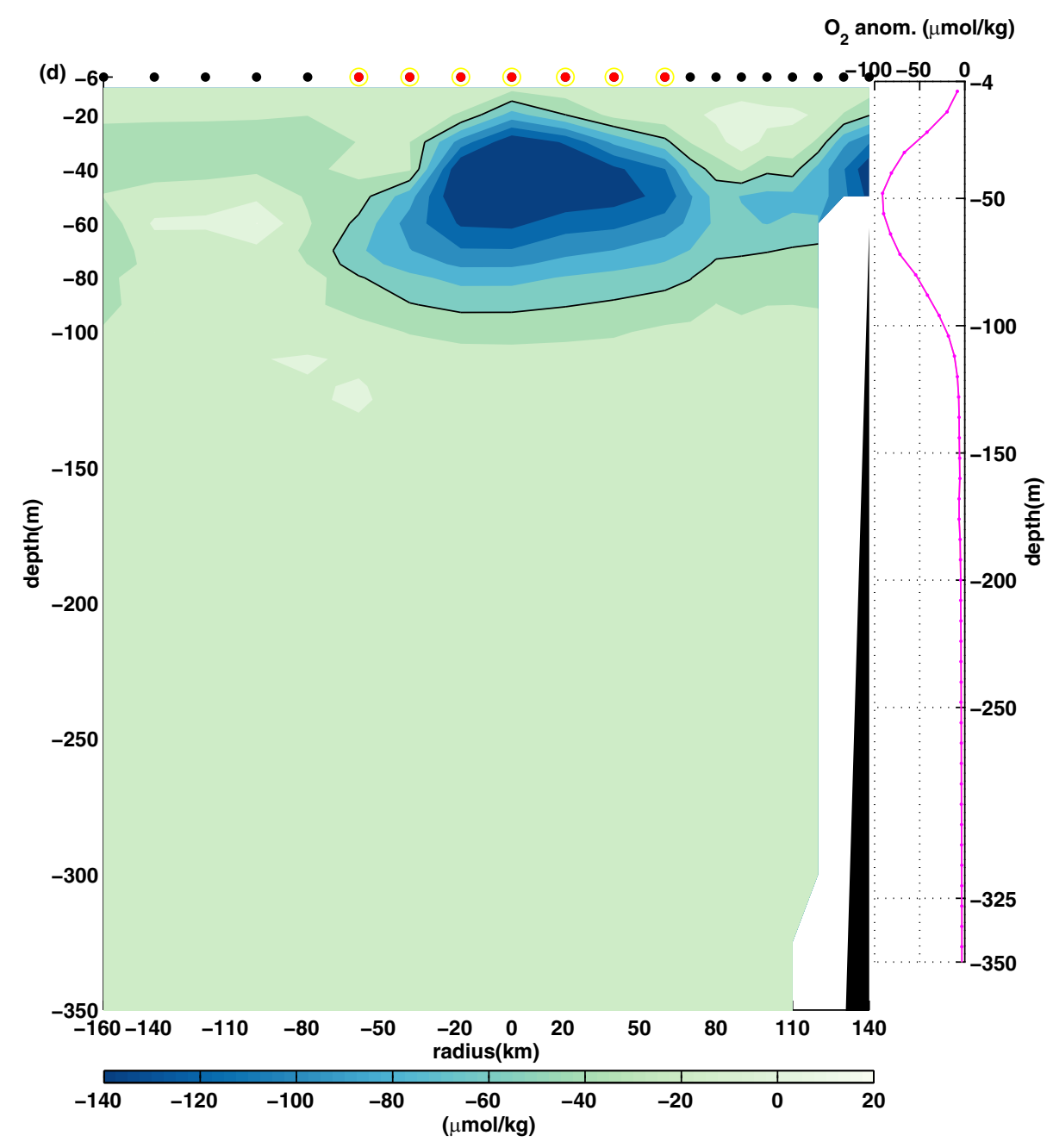

Figure 10. (continued)

orbital gradient flow velocity and the mean geostrophic velocity $\left(v-v_{g}\right)$, within the vortex core. (7) Nonlinearity parameter $(U / c)$, defined as the ratio between the maximum orbital velocity mean $(U)$, where each orbital velocity mean corresponds to each closed geopotential anomaly contour within the eddy, and the drift velocity of the vortex (c) [Chelton et al., 2011; Chaigneau et al., 2011]. If this ratio is higher than 1 the eddy can be considered as nonlinear and it can trap and carry fluid within its core [Flierl, 1981]. (8) Orbital velocity defined as the mean speed inside the eddy (from LADCP data).

[27] Figure 13 shows the vertical profiles of the properties described above. In general, all the profiles show a decrease of the vortex strength with depth with its fastest rate of change located between the surface and the thermocline. Also, from 0 to $100 \mathrm{~m}$ depth, most of them show a quasi-constant value. Table 1 summarizes the mean values of the dynamical properties estimated within the CE core. In the case of the eddy amplitude (Figure 13a, blue line), 1 $\mathrm{cm}$ was defined as the minimum geopotential anomaly displacement that can be measured by the CTD, suggesting a first proxy for the vertical extent of the eddy $(\sim 750 \mathrm{~m})$. Coincidently, this depth was approximately the same depth observed for the flattened $\sigma_{\theta}$ isopleths (Figure 10a). The
CE diameter remained almost constant with depth showing a mean value of $130 \mathrm{~km}$, although weak local variations can be observed (Figure 13a, red line). The normalized relative vorticity profile $(\zeta / f$, Figure $13 \mathrm{~b}$, blue line), showed a mean value of 0.48 , with its greatest value $(\sim 0.8)$ from 0 to $100 \mathrm{~m}$, similar to its vertical distribution along E-transect (Figure 12). The rotational period ( $T$, Figure 13b, red line) was almost constant from the surface down to $\sim 100 \mathrm{~m} \mathrm{(24}$ days), although it showed longer rotational periods with depth, often caused by the baroclinicity of the eddy. $T$ should be treated as a function of depth, and instead of thinking that the eddy was rotating as a solid body, it should be thought as a stack of rigid bodies in rotation [Takahashi et al., 2007].

[28] As explained before, the comparison of the orbital gradient flow velocity $(v)$ against the geostrophic velocity $\left(v_{g}\right)$, gives an estimate of the importance of the centrifugal force for the eddy dynamics. This last force is not included in the geostrophic balance but the difference between the orbital gradient flow velocity and the geostrophic velocity $\left(v-v_{g}\right)$ shows its contribution, referred to as ageostrophy. As expected for a cyclonic eddy, the geostrophic velocity was higher than the gradient velocity (blue line in Figure 13c); the ageostrophic contribution showed the highest 


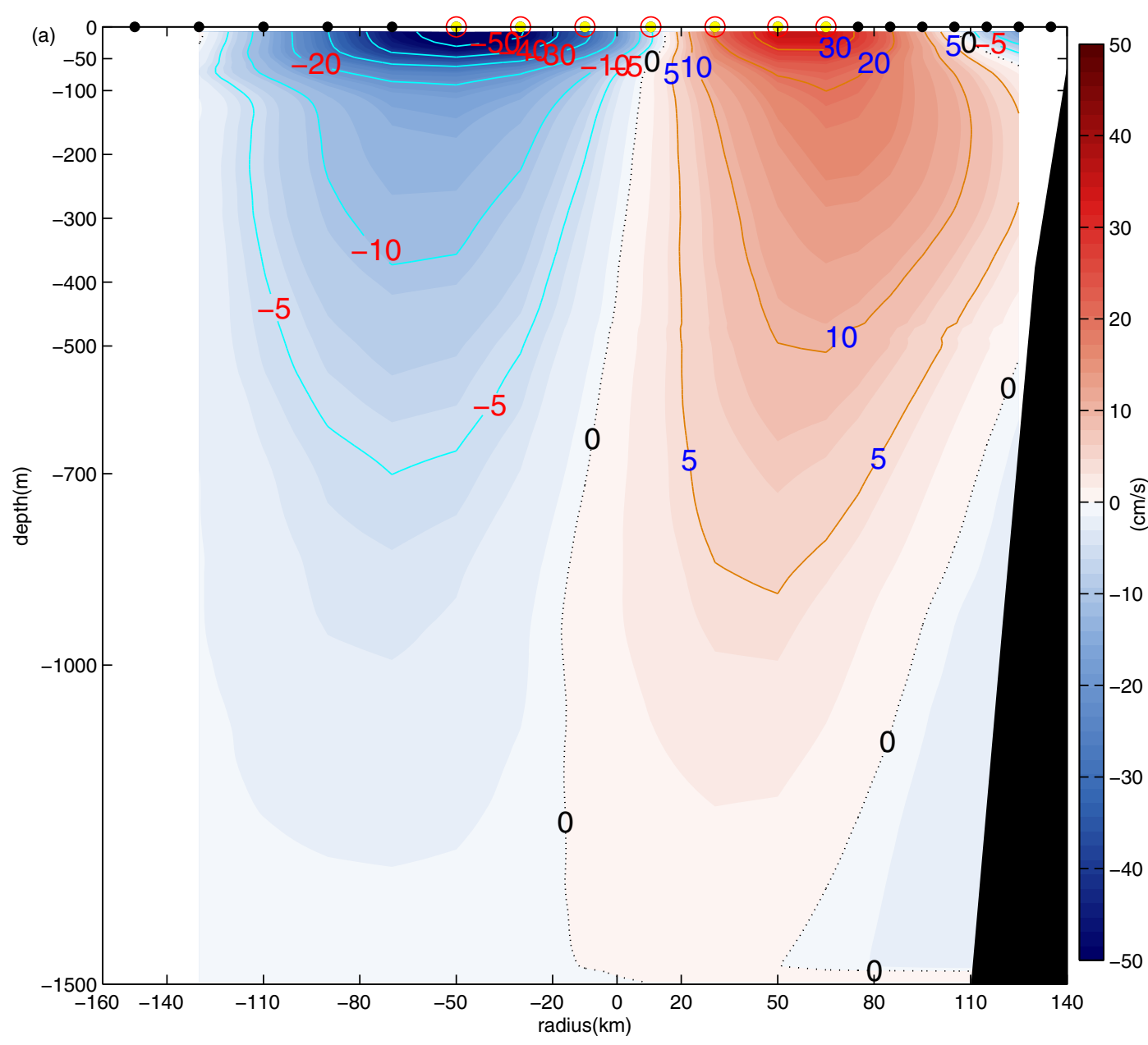

Figure 11. Comparison between the vertical distribution of (a) the geostrophic velocity relative to $1500 \mathrm{~m}$ (from CTD) and (b) the orbital velocity (from the LADCP), for the same transect. Red (blue, respectively) colors show an equatorward (poleward) flow. Dots at the top of the figure indicate the location of the sampling stations, whereas red and yellow dots correspond to the stations located within the CE core.

negative value at the surface and approached zero at 200 $\mathrm{m}$, suggesting that deeper in the water column the centrifugal force was no longer important. In this region, $v_{g}$ was $\sim 1.4$ times greater than $v$. The Rossby number (not shown) is another way of measuring the relative importance of the centrifugal force within the eddy, it showed a mean value of 0.4 from the surface down to $172 \mathrm{~m}$, which is similar to the $50 \%$ overestimation found in the ageostrophy result, indicating that the nonlinear centrifugal force within the eddy is very important, and needs to be taken into account for dynamical analysis, as was done for the gradient flow balance. The EKE (red line in Figure 13c) showed a mean value of $123 \mathrm{~cm}^{2} / \mathrm{s}^{2}$ in this layer $(0-200 \mathrm{~m})$.

[29] Flierl [1981] suggested that the amount of water that an eddy can trap can be estimated as the ratio of its translation speed to its orbital velocity, which is expressed here as the nonlinearity parameter (U/c, Figure $13 \mathrm{~d}$ blue line). To estimate this parameter, there were two values that could be assigned to the translation velocity $(c)$ : the mean translation velocity that this CE had through its life span $(5.1 \mathrm{~cm} / \mathrm{s})$ or the instantaneous translation velocity that it showed for the time that it was sampled $(12.6 \mathrm{~cm} / \mathrm{s})$. For $c=5.1 \mathrm{~cm} / \mathrm{s}$, the nonlinearity parameter was greater than 1 from the surface to $750 \mathrm{~m}$ depth, which in principle shows that for the whole region inside the eddy, it can promote mixing and transport the fluid trapped within its limits. Nevertheless, the heat, salt content, and dissolved oxygen along with the other dynamical properties just shown above, showed that it is in the surface waters that this CE impacted more these properties. In the case of $c=12.6 \mathrm{~cm} / \mathrm{s}$, this parameter was $>1$ from the surface to $172 \mathrm{~m}$ depth, which is more consistent with the thermodynamical and kinematic results. The last profile shown is the mean orbital velocity $(\mathrm{cm} / \mathrm{s}$, Figure $13 \mathrm{~d}$ red line), which showed a quasi-constant value from 0 to $100 \mathrm{~m}(16.8 \mathrm{~cm} /$ $\mathrm{s})$, and greater than $5 \mathrm{~cm} / \mathrm{s}$ in the whole profile $(0-750 \mathrm{~m})$.

[30] Figure 14 shows the quasi-tubular shape of this structure with depth, where the volume of water trapped within the core can be approximated as the volume of a cylinder $\left(\pi r^{2} h\right)$ having a mean radius $(r)$ of $65 \mathrm{~km}$ and a height (h) of $172 \mathrm{~m}$, as demonstrated by the thermodynamical and kinematic results, which gives a volume estimate of $2.3 \times$ 


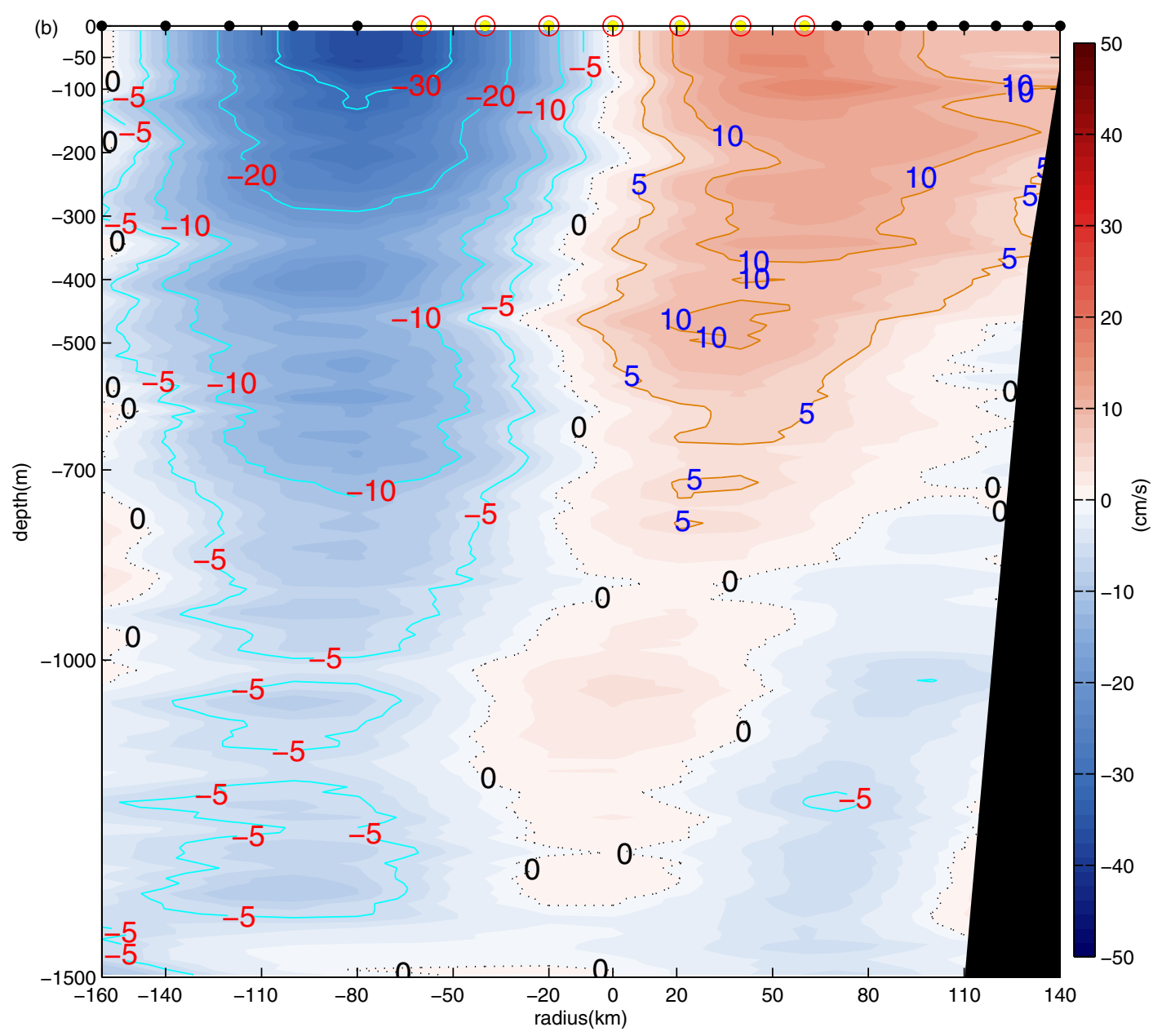

Figure 11. (continued)

$10^{12} \mathrm{~m}^{3}$. The net annual transport that cyclonic eddies can generate off Cabo Corrientes can be estimated from the properties obtained for this particular eddy, but first a verification that this CE is a representative sample of the population of cyclonic eddies for this region is needed. Following the work of Chaigneau et al. [2011], a comparison between the surface properties of this cyclone and the statistical results of the population of cyclonic eddies for Cabo Corrientes provided by Kurczyn et al. [2012] (their Table 1) was done. It was found that this eddy lies within their mean statistical interval; therefore, it can be considered as a representative sample. Proceeding with the calculations, the volume of water trapped within the core of this eddy was divided by 1 year, to obtain a mean annual flux of $0.07 \mathrm{~Sv}$. Then, knowing that in the mean four cyclonic eddies are generated per year in Cabo Corrientes [Kurczyn et al. 2012, their Table 2], multiplying this mean annual flux by 4 , gives a net annual transport of $0.30 \mathrm{~Sv}$ for cyclonic eddies in Cabo Corrientes.

[31] Figure 15 synthetises the dynamical visualization of the $\mathrm{CE}$, by combining remote and direct observations. The bowl shape of the sea level displacement (typical of cyclonic eddies) along with its associated geostrophic flow, taken from the SLA map shows its surface expression. In the vertical, the normalized relative vorticity, derived from the LADCP velocity field, show the vertical extent of this vortex $(0-750 \mathrm{~m})$, at the time it was sampled. This figure illustrates the usefulness of combining both types of observational tools, which gives an idea of the shape and extent that these mesoscale structures can have in the real ocean.

\section{Discussion}

[32] The results presented above show that cyclonic eddies in the northeastern Pacific tropical-subtropical transition zone can live for long periods ( $\sim 6$ months, as presented by Kurczyn et al., [2012]) and are important structures that help redistribute ocean properties; contrary to what numerical models have shown [Zamudio et al., 2007; Pantoja et al., 2012]. This particular observation exhibited a strong cyclone that accounted for a disproportionate fraction of the total heat transport in the region, which is not the case for all mesoscale eddies that are generated here. Together with the anticyclonic eddies, they have an important impact on the long-term circulation of the region (as shown by Godinez et al. [2010]).

\subsection{Eddy Generation}

[33] Figure 6 shows a moderate wind stress curl event that promoted an upwelling event that influenced the 


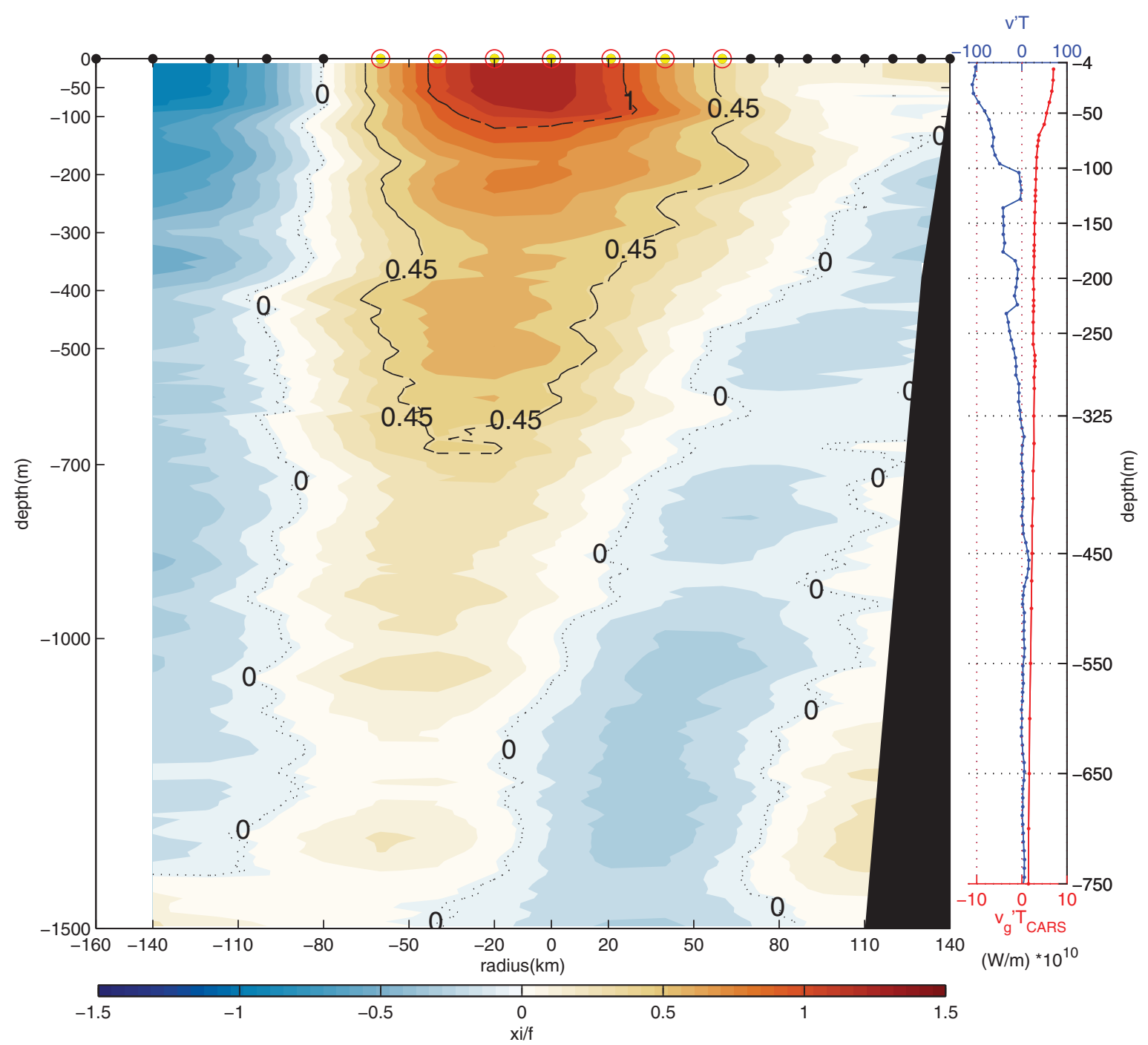

Figure 12. (left) Vertical distribution of normalized vorticity $(\zeta / f)$ along the E-transect of the PROCOMEX-0511 cruise, showing the positive vorticity associated with the CE. A positive vorticity of the order of 1 is shown between 0 and $100 \mathrm{~m}$ (where the anoxic water was found), the edge of the eddy core seems to be marked by the 0.45 contour. (right) Meridional heat transport integrated over the radius within the region of the eddy: In blue is the in situ meridional heat transport $\left(v^{\prime} T\right)$, in red is CARS climatological heat transport for November $\left(\mathrm{v}_{g}^{\prime} T_{C A R S}\right)$. Dots at the top of the figure indicate the location of the sampling stations, where red and yellow dots corresponds to the stations located within the CE core.

generation of this cyclonic eddy; however, Kurczyn et al. [2012] showed that cyclonic eddy production off Cabo Corrientes presents a semiannual behavior (their Figure 12c), with one peak in May, related to the upwelling maximum in spring. Therefore, downwelling events dominate during November indicating that our upwelling event was a not a very common feature to expect during this month. On the other hand, the second peak of semiannual eddy production was found in October and it is related to a coastal equatorward flow (their Figure 1c), showing that surface currents are important too for the generation of eddies in this region. Figures 7 and 8 suggest an involvement of a strong equatorward flow in the generation of this coherent structure. Thus, the generation of this cyclone should be attributed to a combination of factors, where an unexpected upwelling event occurred simultaneously with the interaction between an equatorward flow located close to the coast.

\subsection{Comparison Against SLA Satellite Observations}

[34] The comparison of some of the surface properties derived from altimeter data and the eddy detection method against the observations brought by the in situ data (Table 2) should be approached carefully. In the case of the eddy diameter, the two observations refer to different measurements since the ocean survey only sampled the eddy core; thus they complement each other, while the satellite observations show the real size of this $\mathrm{CE}$, the in situ diameter represents the size of its core. In the case of the CE kinematics, both observations refer to the most dynamical region within the eddy (its core) and therefore can be 

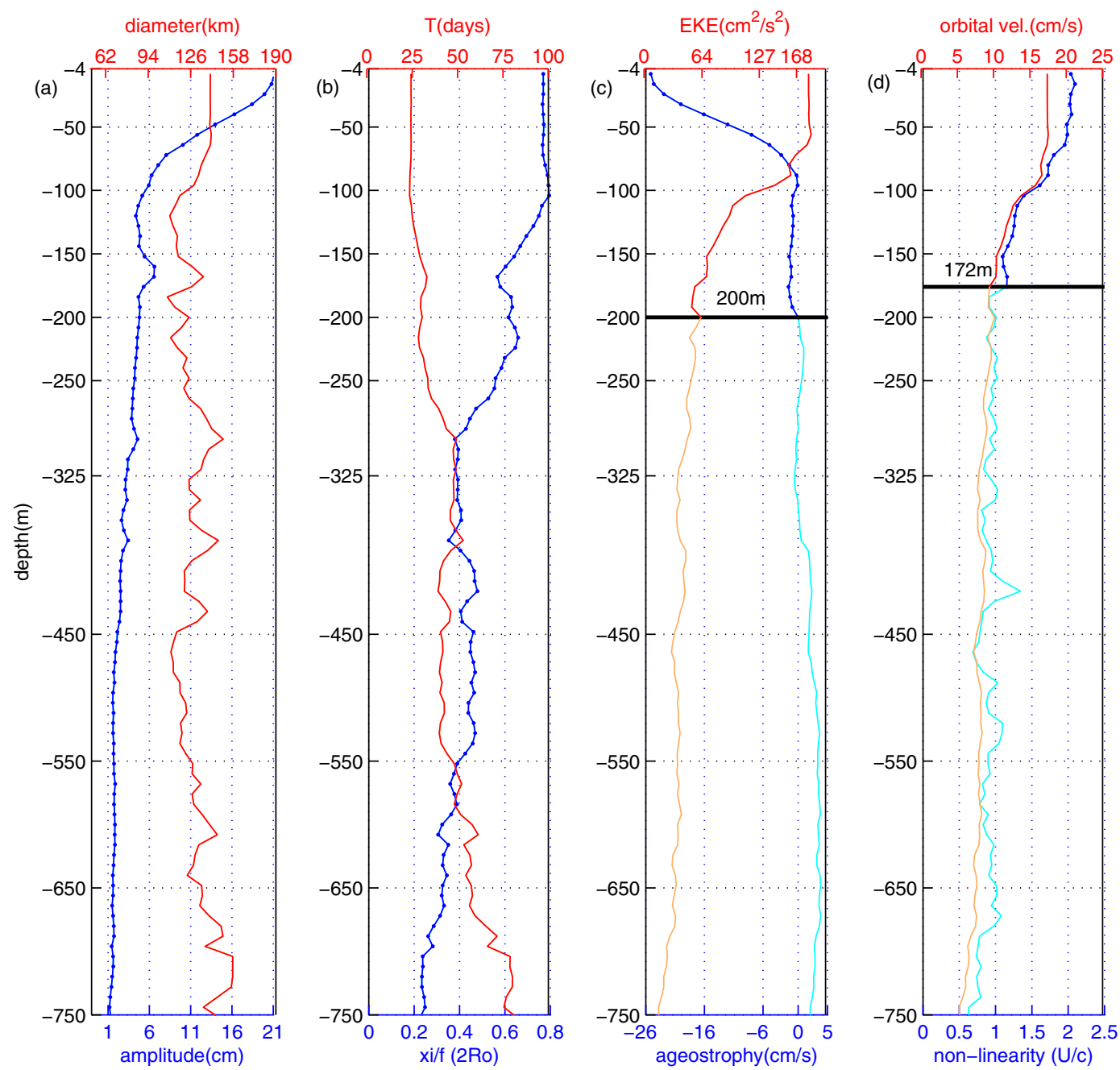

Figure 13. Mean vertical profiles of different eddy properties averaged within the CE core: (a) amplitude (in $\mathrm{cm}$ ) and diameter (in $\mathrm{km}$ ), (b) normalized relative vorticity $(\zeta / f$ ) and rotational period $\mathrm{T}$ (in days), (c) ageosotrophy (in $\mathrm{cm} / \mathrm{s}$ ) and EKE (in $\mathrm{cm}^{2} / \mathrm{s}^{2}$ ), and (d) nonlinearity parameter (U/c) and orbital velocity (in $\mathrm{cm} / \mathrm{s}$ ). Horizontal black lines indicate the depth of the influence of the cyclone, as suggested by the variable studied.

compared. In this case, the altimeter observations seem to underestimate the real kinematics since the in situ data showed higher $v_{g}$, EKE, and $U$, which could be attributed to the filtering of the AVISO SLA product and its coarse spatial grid $\left(1 / 4^{\circ}\right)$.

\section{Conclusions}

[35] After having analyzed the physical features of this cyclonic eddy from remote observations (SLA, surface winds, SST, and CHL), and direct observations (LADCP and CTD data), the life story of this coherent structure was reconstructed for the time it was generated near the coast until its dissipation nearly 8 months later, and having traveled $1020 \mathrm{~km}$ into the open ocean. With the help of surface winds, CHL and SST, the forcing involved in the generation of this negative vortex were studied, and it is suggested that it was caused by the simultaneous occurrence of an upwelling event and an intensified equatorward flow located close to the coast. From the ocean survey

Table 2. Remote and Direct Observations of Mean Surface Properties of the Cyclone

\begin{tabular}{lccccc}
\hline Surface Observation & Diameter $(\mathrm{km})$ & Amplitude $(\mathrm{cm})$ & Orbital Velocity $(\mathrm{cm} / \mathrm{s})$ & $U(\mathrm{~cm} / \mathrm{s})$ \\
\hline Altimeter & 221 & -10.0 & 24.2 & 368 \\
Cruise & 141 & -21.1 & $v_{g}(\mathrm{CTD})$ & 42.5 & 1006 \\
& & & $v$ (LADCP) & 17.4 & 58.1 \\
\hline
\end{tabular}




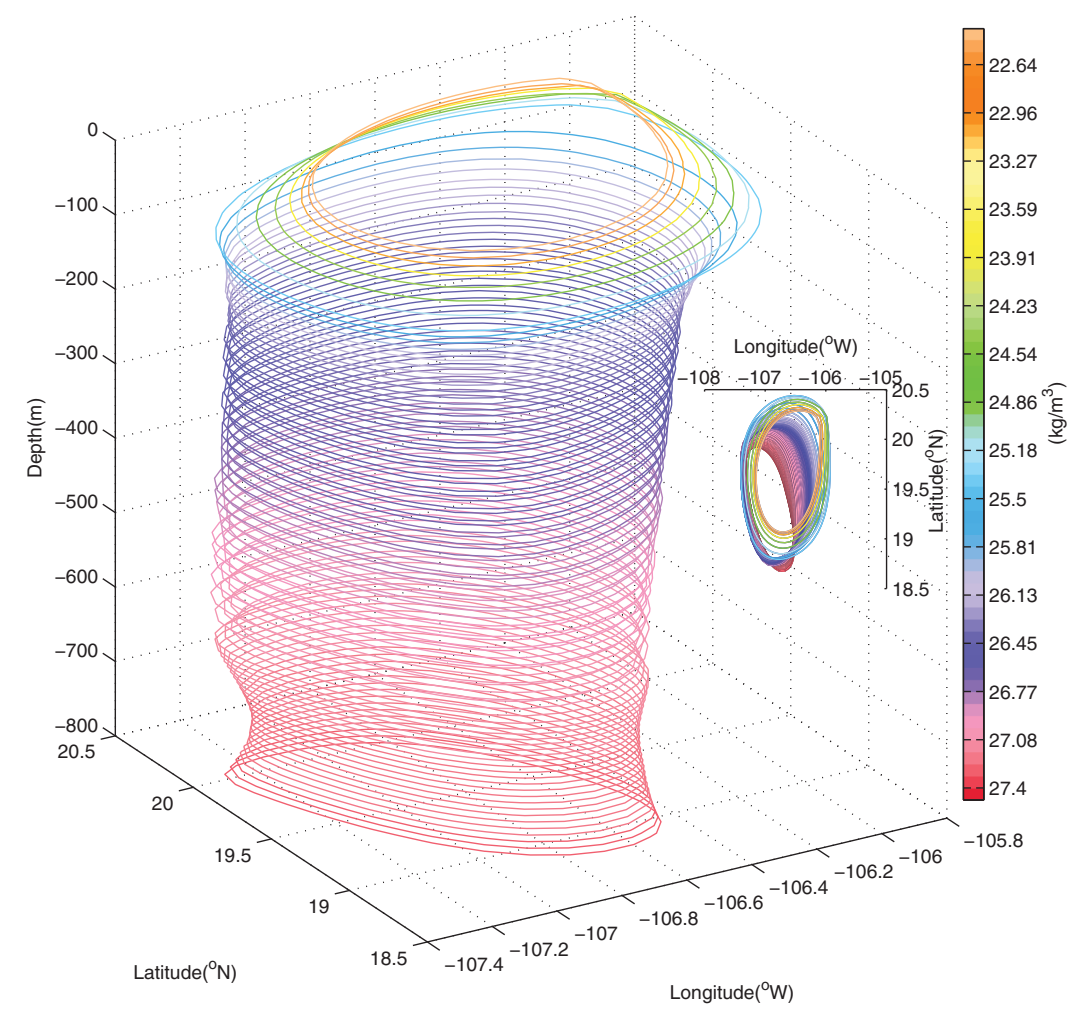

Figure 14. Conceptual diagram of the shape of the cyclone, derived from the geopotential anomaly contours that intersect with the $\zeta_{c}$ at the different depths, and represent the outermost closed geopotential anomaly contour associated with the eddy center. The colors show the mean $\sigma_{\theta}$ associated within each contour.

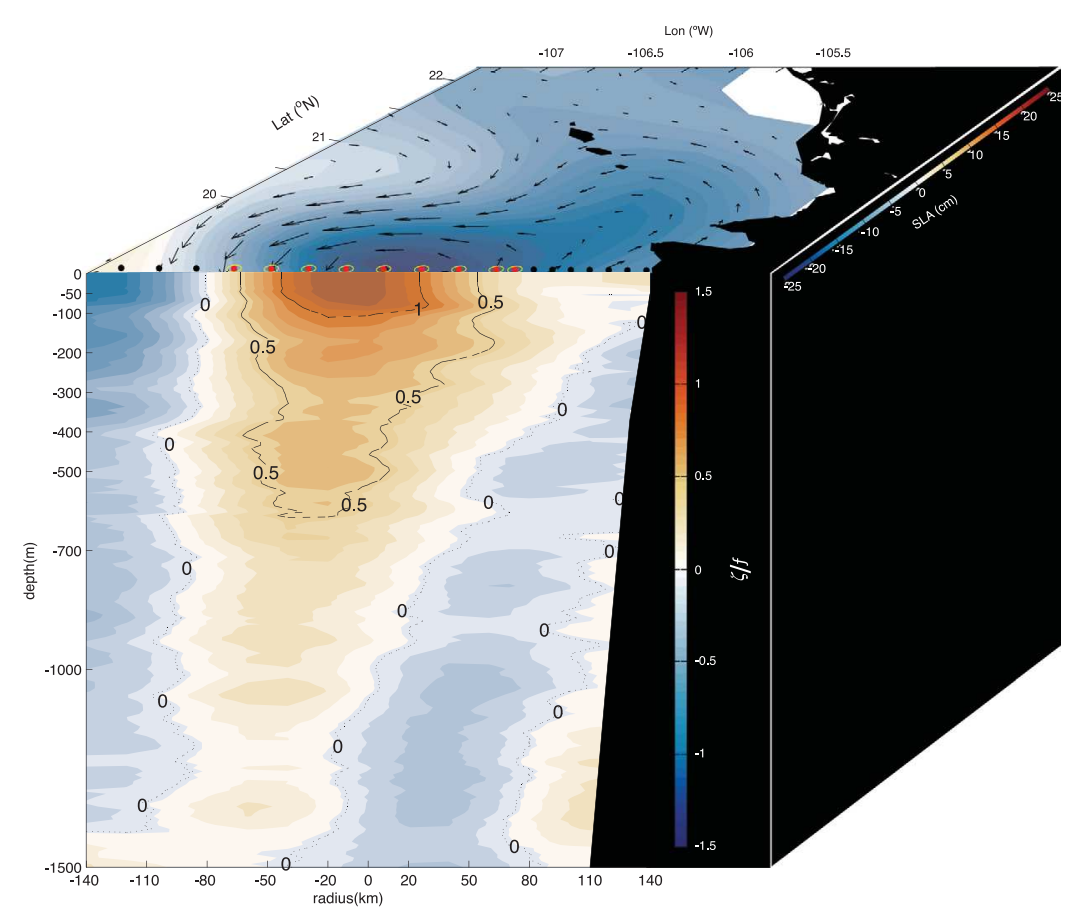

Figure 15. Schematic diagram of the cyclone. Its surface signature is given by the SLA data with its corresponding geostrophic flow; whereas in the vertical, the ship-based observations of the normalized relative vorticity show its extent in the water column $(0-750 \mathrm{~m})$. 
observations, the characteristics of this CE were calculated, revealing its presence to $750 \mathrm{~m}$ depth, but showing that its influence occurred mainly in the first $100 \mathrm{~m}$, where it brought up colder, saltier and anoxic waters, with the signature of the Subtropical Subsurface water. The kinematical result showed an eastward shift of the eddy axis from depth to the sea surface, of $1.5^{\circ}$ of longitude, which was not evident in the thermodynamic fields. This axis tilt promoted a total meridional heat transport of $-105 \times 10^{12} \mathrm{~W}$ integrated within the region of the eddy, accounting for a disproportionate fraction of the total heat transport in the region, one order of magnitude greater than the climatological geostrophic currents from CARS climatology, showing that cyclonic eddies in the northeastern Pacific tropicalsubtropical transition zone are important structures that help redistribute ocean properties.

[36] Acknowledgments. This is a product of project "Investigaciones Oceanográficas del Sistema Frontal de Baja California Sur" supported by CONACyT (SEP-2008-103898, PI EB). J.A.K. was recipient of a CONA$\mathrm{CyT} \mathrm{PhD}$ scholarship. Additional support was received from CICESE internal budget. The altimeter product were produced by Ssalto/Duacs and distributed by AVISO, with support from CNES. Many thanks to Julio Sheinbaum, Paula Pérez-Brunius, Luis Zavala, and two anonymous reviewers for their comments and contributions to this study, and also Max Lizárraga for his help with the last figure.

\section{References}

Atlas, R., R. N. Hoffman, J. Ardizzone, S. M. Leidner, J. C. Jusem, D. K. Smith, and D. Gombos (2011), A cross-calibrated, multiplatform ocean surface wind velocity product for meteorological and oceanographic applications, Bull. Am. Meteorol. Soc., 92, 157-174, doi:10.1175/2010BAMS2946.1.

Barton, E. D., M. L. Argote, J. Brown, P. M. Kosro, M. Lavín, J. M. Robles, R. L. Smith, A. Trasviña, and H. S. Velez (1993), Supersquirt: Dynamics of the Gulf of Tehuantepec, México, Oceanography, 6(1), 23-30.

Barton, E. D., M. F. Lavín, and A. Trasviña (2009), Coastal circulation and hydrography in the Gulf of Tehuantepec, Mexico, during winter, Cont. Shelf Res., 29, 485-500.

Bennett, A. F., and W. B. White (1986), Eddy heat flux in the subtropical North Pacific, J. Phys. Oceanogr., 16, 728-740.

Chaigneau, A., and O. Pizarro (2005), Eddy characteristics in the eastern South Pacific, J. Geophys. Res., 110, C06005, doi:10.1029/ 2004JC002815

Chaigneau, A., G. Eldin, and B. Dewitte (2009), Eddy activity in the four major upwelling systems from satellite altimetry (1992-2007), Prog. Oceanogr., 83, 117-123.

Chaigneau, A., M. Le Texier, G. Eldin, C. Grados, and O. Pizarro (2011), Vertical structure of mesoscale eddies in the eastern South Pacific Ocean: A composite analysis from altimetry and Argo profiling floats, J. Geophys. Res., 116, C11025, doi:10.1029/2011JC007134.

Chelton, D. B., M. H. Freilich, and S. K. Esbensen (2000a), Satellite observations of the wind jets off the Pacific coast of Central America. Part I: Case studies and statistical characteristics, Mon. Weather Rev., 128, 1993-2018.

Chelton, D. B., M. H. Freilich, and S. K. Esbensen (2000b), Satellite observations of the wind jets off the Pacific Coast of Central America. Part II Regional relationships and dynamical considerations, Mon. Weather Rev., 128, 2019-2043.

Chelton, D. B., M. G. Schlax, and R. M. Samelson (2011), Global observations of nonlinear mesoscale eddies, Prog. Oceanogr., 91, 167-216.

Clarke, A. J. (1988), Inertial wind path and sea surface temperature patterns near the Gulf of Tehuantepec and Gulf of Papagayo, J. Geophys. Res., 93, 15,491-15,501.

Flierl, G. R. (1981), Particle motions in large-amplitude wave fields, Geophys. Astrophys. Fluid Dyn., 18, 39-74, doi:10.1080/0309192810 8208773 .
Godínez, V. M., E. Beier, M. F. Lavín, J. García, and C. E. Cabrera (2006), Datos hidrográficos frente a Cabo Corrientes y en la entrada del golfo de california durante junio del 2005: campaña PROCOMEX-0506, Informe Técnico. Serie Oceanografía Física. CICESE. Febrero 2006.

Godínez, V. M., E. Beier, M. F. Lavín, and J. A. Kurczyn (2010), Circulation at the entrance of the Gulf of California from satellite altimeter and hydrographic observations, J. Geophys. Res., 115, C04007, doi:10.1029/ 2009JC005705.

Henson, S. A., and A. C. Thomas (2008), A census of oceanic anticyclonic eddies in the Gulf of Alaska, Deep Sea Res., Part I, 55, 163-176, doi:10.1016/j.dsr.2007.11.005.

Kundu, P. K., and I. Cohen (2002), Fluid Mechanics, 730 p., Academic Press, San Diego, Calif.

Kurczyn, J. A., E. Beier, M. F. Lavín, and A. Chaigneau (2012), Mesoscale eddies in the northeastern Pacific tropical-subtropical transition zone: Statistical characterization from satellite altimetry, J. Geophys. Res., 117, C10021, doi:10.1029/2012JC007970.

Liang, J.-H., J. C. McWilliams, J. Kurian, F. Colas, P. Wang, and Y. Uchiyama (2012), Mesoscale variability in the northeastern tropical Pacific: Forcing mechanisms and eddy properties, J. Geophys. Res., 117, C07003, doi:10.1029/2012JC008008.

Lluch-Cota, S. E., S. Álvarez-Borrego, E. M. Santamaría-del Ángel, F. E. Müller-Karger, and S. Hernández-Vázquez (1997), The Gulf of Tehuantepec and adjacent areas: Spatial and temporal variation of satellite-derived photosynthetic pigments, Ciencias Marinas, 23(3), 329-340.

McCreary, J. P., Jr., H. S. Lee, and D. B. Enfield (1989), The response of the coastal ocean to strong offshore winds: With application to circulations in the Gulfs of Tehuantepec and Papagayo, J. Mar. Res., 47, 81109.

Morrow, R., F. Birol, D. Griffin, and J. Sudre (2004), Divergent pathways of cyclonic and anti-cyclonic ocean eddies, Geophys. Res. Lett., 31, L24311, doi: 10.1029/2004GL020974.

Olson, D. B. (1980), The physical oceanography of two rings observed by the cyclonic ring experiment. Part II: Dynamics, J. Phys. Oceanogr., 10, 514-528.

Palacios, D. M., and S. J. Bograd (2005), A census of Tehuantepec and Papagayo eddies in the northeastern tropical Pacific, Geophys. Res. Lett., 32, L23606, doi:10.1029/2005GL024324.

Pantoja, D. A., S. G. Marinone, A. Parés-Sierra, and F. Gómez-Valdivia (2012), Numerical modeling of seasonal and mesoscale hydrography and circulation in the Mexican Central Pacific, Ciencias Marinas, 38(2), 363-379.

Parés-Sierra, A., W. B. White, and C.-K. Tai (1993), Wind-driven coastal generation of annual mesoscale eddy activity in the California Current, J. Phys. Oceanogr., 23(6), 1110-1121.

Pingree, R. D., and B. Le Cann (1992), Three anti-cyclonic Slope Water Oceanic eddies (SWODDIES) in the Southern Bay of Biscay, Deep Sea Res., Part A, 39, 1147-1175.

Ridgway, K. R., J. R. Dunn, and J. L. Wilkin (2002), Ocean interpolation by four-dimensional weighted least squares: Application to the waters around Australasia, J. Atmos. Oceanic Technol., 19, 1357-1375, doi:10.1175/1520-0426(2002)019<1357:OIBFDW>2.0. $\mathrm{CO} ; 2$.

Roemmich, D., and J. Gilson (2001), Eddy transport of heat and thermocline waters in the North Pacific: A key to interannual/decadal climate variability?, J. Phys. Oceanogr., 31, 675-687.

Rossby, T., C. Flagg, P. Ortner, and C. Hu (2011), A tale of two eddies: Diagnosing coherent eddies through acoustic remote sensing, J. Geophys. Res., 116, C12017, doi:10.1029/2011JC007307.

Sangrà, P., M. Auladell, A. Marrero-Díaz, J. L. Pelegrí, E. Fraile-Nuez, A. Rodríguez-Santana, J. M. Martín, E. Mason, and A. Hernandez-Guerra (2007), On the nature of oceanic eddies shed by the Island of Gran Canaria, Deep Sea Res., Part I, 54, 687-709.

Stegmann, P. M., and F. Schwing (2007), Demographics of mesoscale eddies in the California Current, Geophys. Res. Lett., 34, L14602, doi:10.1029/2007GL029504.

Stumpf, H. G., and R. V. Legeckis (1977), Satellite observations of mesoscale eddy dynamics in the eastern tropical Pacific Ocean, J. Phys. Oceanogr., 7, 648-658.

Takahashi, D., K. Kido, Y. Nishida, N. Kobayashi, N. Higaki, and H. Miyake (2007), Dynamical structure and wind-driven upwelling in a summertime anticyclonic eddy within Funka Bay, Hokkaido, Japan, Cont. Shelf Res., 27, 1928-1946. 
Thurnherr, A. M. (2011), Vertical velocity from LADCP data, Div. of Ocean and Clim. Phys., Lamont-Doherty Earth Obs. [Available at ftp.ldeo.columbia.edu/pub/LADCP/papers.]

Trasviña, A., and E. D. Barton (2008), Summer circulation in the Mexican tropical Pacific, Deep Sea Res., Part I, 55, 587-607.

Trasviña, A., E. D. Barton, J. Brown, J. H. S. Velez, P. M. Kosro, and R. L. Smith (1995), Offshore wind forcing in the Gulf of Tehuantepec Mexico: The asymmetric circulation, J. Geophys. Res., 100(C10), 20,649-20,663.

Trenberth, K. E., G. J. Olson, and W. H. Large (1989), A global ocean wind stress climatology based on ECMWF analyses, NCAR Tech. Note TN-
338+STR, Clim. and Global Dyn. Div., Natl. Cent. for Atmos. Res., Boulder, Colo.

van Aken, H. M. (2002), Surface currents in the Bay of Biscay as observed with drifters between 1995 and 1999, Deep Sea Res., Part I, 49, 1071-1086.

Zamudio, L., H. E. Hurlburt, E. J. Metzger, S. L. Morey, J. J. O’Brien, C. Tilburg, and J. Zavala-Hidalgo (2006), Interannual variability of Tehuantepec eddies, J. Geophys. Res., 111, C05001, doi:10.1029/2005JC003182.

Zamudio, L., H. E. Hurlburt, E. J. Metzger, and C. E. Tilburg (2007), Tropical wave-induced oceanic eddies at Cabo Corrientes and the Marla Islands, Mexico, J. Geophys. Res., 112, C05048, doi:10.1029/2006JC004018. 